\title{
LA DATA EN LOS DIPLOMAS DEL EMPERADOR ENRIQUE IV Y DE SU ÉMULO ALFONSO VI DE LEÓN
}

\section{THE DATE IN THE DOCUMENTS OF THE EMPEROR HENRY IV AND HIS EMULOUS ALPHONSO VI OF LEÓN}

\author{
NICOLÁS ÁVILA SEOANE \\ Universidad Complutense de Madrid
}

\begin{abstract}
Resumen: Estudio diplomático comparado de cada uno de los parámetros que contempla la data en los documentos emitidos por las respectivas cancillerías de los reinados, casi sincrónicos, del titular de la corona imperial Enrique IV y el autoproclamado emperador de España Alfonso VI de León. Con el siguiente desglose: posición dentro del diploma; palabras introductorias; día, semana y mes; año; años del reinado y regnante; data tópica; otras referencias cronológicas, y aprecación.

Palabras clave: Diplomática comparada, datación, Plena Edad Media, León, Sacro Imperio Romano Germánico.
Abstract: Comparative diplomatic study of each one of the parameters which constitute the date in the documents issued by the respective chancelleries of the reigns, almost synchronous, of the imperial crown holder Henry IV and the self-proclaimed emperor of Spain Alphonso VI of León. With the following breakdown: position in the diploma; introductory words; day, week and month; year; reign's years and regnante; geographical date; other chronological references, and apprecatio.

Keywords: Comparative Diplomatics, date, High Middle Ages, León, Holy Roman Empire.

A finales del siglo XI y principios del XII dos reyes europeos se titulaban emperadores mientras el pontífice Gregorio VII (1073-1085) iniciaba una lucha para conseguir el sometimiento a la tiara de cualquier otra corona y muy especialmente la imperial, lo cual originó la llamada Querella de las Investiduras porque también se planteaba la intromisión de las autoridades laicas en el nombramiento de obispos ${ }^{1}$.

Enrique IV de Alemania (1056-1105) fue el mayor antagonista de Gregorio VII y Urbano II (1088-1099): excomulgado en dos ocasiones, servil penitente en

\footnotetext{
${ }^{1}$ Puede consultarse una bibliografía básica sobre la cuestión en el manual de V. Á. ÁLVAREZ PALENZUELA, Historia universal de la Edad Media, Barcelona, 2002, pp. 450-451.
} 
Canossa y luego sitiador del papa; por su parte Alfonso VI de León (1065-1109), firme aliado de los monjes cluniacenses, tras algunas resistencias iniciales, se alineó con el pontificado, bajo cuya influencia impuso en sus reinos el rito romano y la escritura carolina. En cuanto a la desigual dignidad imperial de uno y otro, el leonés asumió por su cuenta el título de imperator totius Hispaniae², y el alemán fue coronado en 1084 por el antipapa Clemente III, nombrado ex profeso para ello: Clementem papam ad electionem omnium instituit, a quo ipse communi omnium favore consecratus imperator et patricius factus ${ }^{3}$.

Los diplomas de uno y otro reflejarán el intento de soslayar esa originaria y compartida tacha de legitimidad, y precisamente la fecha, junto con la intitulación, serán las partes preferidas para hacerlo. Pero el estudio conjunto de las datas de Enrique IV y Alfonso VI se justifica además por los significativos cambios que implantaron una y otra cancillería: en el Sacro Imperio va desapareciendo la ältere Datierung o fecha antigua ${ }^{4}$, y León empieza a aplicar reformas que cristalizarán algo después cuando Alfonso VII institucionalice definitivamente la cancillería: adopción del regnante; paulatino aumento del uso de la data tópica, e incorporación de nombres preeminentes o acontecimientos políticos y militares ${ }^{5}$.

Las fuentes esenciales que sustentan este trabajo son dos colecciones diplomáticas: la de Dietrich von Gladiss y Alfred Gawlik (Die Urkunden Heinrichs IV, 1941-1978, volumen VI de los Monumenta Germaniae Historica) y la de Andrés

2 A. GAMBRA GUTIÉRREZ, Alfonso VI. Cancillería, curia e imperio, vol. I, León, 1997, pp. 696-702, enumera los motivos que confluyeron en esta decisión de Alfonso VI: la idea de supremacía del reino de León sobre las demás monarquías peninsulares; el rechazo a la pretensión de Gregorio VII, manifestada en junio de 1077, del dominio temporal sobre España, aduciendo que desde la antigüedad había sido patrimonio de San Pedro; enfrentarse a la alianza entre el papa y Sancho V de Aragón, que venía fraguándose desde la cruzada de Barbastro de 1064 (por el mismo motivo se buscó el acercamiento a la poderosa orden de Cluny); la crisis del cambio de rito que se desarrolló entre 1077 y 1080; el pago de parias por los reyes de Granada a partir de 1075, que suponía el control de todas las taifas principales, y sobre todo la conquista de La Rioja en 1076. La tensión con Gregorio VII terminó cediendo y Alfonso VI se convirtió en el principal impulsor de la liturgia romana, impuesta en León y Castilla en el concilio de Burgos de 1080 (J. F. O'CALLAGHAN, "The integration of christian Spain into Europe: the role of Alfonso VI of León-Castile”, en B. F. REILLY (ed.), Santiago, Saint-Dénis and Saint Peter. The reception of the Roman liturgy in León-Castile in 1080, Nueva York, 1985, pp. 102-113).

${ }^{3}$ C. TORRES DELGADO y A. POCIÑA PÉREZ (eds.), Vida del emperador Enrique IV de Alemania, Granada, 1983, p. 59.

${ }^{4}$ H. BRESSLAU, Manuale di Diplomatica per la Germania e l'Italia, Roma, 1998, p. 1072. La edición príncipe alemana del Handbuch der Urkundenlehre für Deutschland und Italien se publicó en 1889; aquí citaré por la traducción italiana de Anna Maria Voci-Roth.

${ }^{5}$ S. CABEZAS FONTANILLA y N. ÁVILA SEOANE, "Cómo fechaba la oficina real asturleonesa y castellana hasta el siglo XII”, en J. C. GALENDE DÍAZ y J. DE SANTIAGO FERNÁNDEZ (dirs.), X Jornadas científicas sobre documentación: el calendario y la datación histórica, Madrid, 2011, p. 87. 


\section{Nicolás Ávila SEOANE \\ LA DATA EN LOS DIPLOMAS DEL EMPERADOR ENRIQUE IV Y DE SU ÉMULO ALFONSO VI DE LEÓN}

Gambra Gutiérrez (Alfonso VI. Cancillería, curia e imperio, 1997-1998). De los 687 documentos que acumulan ambos repertorios, se han seleccionado los intitulados por los propios monarcas, con independencia de que fueran expedidos antes o después de proclamarse emperadores, pero exceptuando: las actas que aluden a su presencia, las judiciales, los diplomas del resto de la familia real, y aquellos donde sólo signaron como confirmadores; son en total 447 de Enrique IV y 155 de Alfonso $\mathrm{VI}^{6}$.

\section{POSICIÓN DE LA DATA.}

La inmensa mayoría (422) de los de Enrique IV están datados, y la fecha, salvo en siete, va cerrando el diploma ${ }^{7}$, seguida tan sólo de la aprecación, que centrará el último apartado. En cinco de esos siete casos precede a la validatio, si bien tres de ellos son falsos y los otros dos copias, y los dos restantes, que tampoco son originales sino copias, colocan así la fecha: el E394 ${ }^{8}$, antes de la lista de testigos, y el E405, fragmentada: la crónica, antepuesta a la recognitio (Herimannus cancellarius recognovi), y la tópica, pospuesta, precediendo a la aprecación y el signo imperial. Por tanto, la cancillería imperial de Enrique IV fechaba siempre al concluir, cualquier disparidad indicaría que se trata de falsificaciones, o copias probablemente alteradas.

E280 y E452 llevan doble data. El primero es un falso privilegio en favor del monasterio de Hirsau, del 9 de octubre de 1075, con su fecha ordinaria de expedición (Data est VII idus octobris anno Dominicae Incarnationis millesimo $L X X V$, indictione XIIII, anno autem ordinationis domni quarti Heinrici regis XXI, regni vero XVIIII, actum Wormacie) y, tras la aprecación, otra referida al momento efectivo de la donación, unos días antes: Traditio autem comitis Adalberti facta est apud Hirsaugiam in ipsis foribus aecclesiae anno item Incarnationis Domini-

\footnotetext{
${ }^{6}$ Salvo la etapa inicial de reinado privativo en León (1065-1072), de la que apenas se han conservado ocho diplomas, el ritmo de trabajo de la oficina de Alfonso VI es bastante regular con un máximo de cuatro anuales, menos en 1076 (8), 1077 (10), 1093 (6), 1099 (5), 1100 (7) y 1103 (9). En cambio Enrique IV concentra el cuarenta por ciento de sus emisiones en la primera de las cinco décadas que reinó (156 entre 1056 y 1065), mientras que en las sucesivas la producción decae paulatinamente: 86 en la segunda, 64 en la tercera, 49 en la cuarta y 26 en la quinta. En ambos casos se trata de los indudablemente auténticos y con el año fijado (125 y 381 respectivamente).

${ }^{7}$ Extremo bien conocido; véase por ejemplo H. BRESSLAU, Manuale di Diplomatica..., p. 1018: "in Germania i documenti regi e dei principi furono datati esclusivamente alla fine”.

${ }^{8}$ Las referencias a los documentos de Enrique IV irán con una E y el ordinal de la colección de von Gladiss y Gawlik, y los de Alfonso VI por el de Gambra y una A. Los cinco acabados de citar son E371, E372, E395, E429 y E439.
} 
cae millesimo $L X X V$, indictione XIII, feria II, luna XXX, XVIII kalendas octobris ipsa scilicet festivitate Sancti Aurelii. El otro, un privilegio de confirmación concedido a la diócesis de Bremen y Hamburgo, tiene también la fecha corriente en su posición habitual (Anno Dominice Incarnationis MLXXXXVI, indictione IIII, Heinrico anno XLIII regnante, imperante vero III decimo, data est Patavii, presente et laudante ac confirmante domno papa Clemente, recognoscebant ex principibus episcopus Monasteriensis Erpo, episcopus Veronensis Wolstrigel, Vincentinus episcopus Ecelo, Tarvisianus episcopus Cumpoldus, episcopus Veltrensis Aribo, episcopus Faventinus Routpret, marchiones Azo, Purchardus; comites Megenfridus, Wido, Houc, et alii complures) pero previamente, antes de la validación, introduce una segunda data tópica: Factum est in Italia Verone in monasterio Sancti Zenonis ${ }^{9}$. En los apartados correspondientes iremos viendo los distintos miembros de cada una de ellas.

Igualmente casi todos los diplomas de Alfonso VI, salvo cuatro de los 155 aquí considerados, llevan su fecha, que por regla general (131) se sitúa al final del cuerpo central, dando paso a los elementos de validación ${ }^{10}$; otras cinco veces se añade una cláusula a continuación (A4, A5, A13, A85, A175). Sólo hay 13 con la data en último lugar, a la manera de los de Enrique IV. De los dos restantes, el A104, que es falso, injiere la data en el núcleo documental, y el A143 la deja al principio como las actas.

Dos puntualizaciones: el precepto A63 separa la data crónica de la tópica quedando aquella en su posición habitual, y ésta en línea aparte, al final, tras los signos validativos; por su parte el falso privilegio de confirmación A162 que ratifica las donaciones a la catedral de Oviedo, de las cuales resume seis del propio Alfonso VI, dando de cada una su respectiva fecha, deja en cambio sin concretar la primordial, pues sólo pone facta cartulis testamentorum supradictorum secundum eras uniuscuiusque suprascriptas.

\footnotetext{
${ }^{9}$ Esta concurrencia de lugares puede deberse a que Enrique IV, yendo de Garda (E450) a Padua, se detuvo en Verona, donde tendría lugar la ceremonia de confirmación, y ya en Padua se expediría el diploma (D. VON GLADISS y A. GAWLIK, Die Urkunden Heinrichs IV, vol. I, Berlín, 1941, p. XCIX).

${ }^{10}$ Lo refleja también Andrés Gambra: “dejando de lado los diplomas judiciales y las epístolas, [...] en la mayoría de los diplomas alfonsinos la data abre el escatocolo o protocolo final y se sitúa después de la sanctio [...] y antes de la suscripción real. [...] De tal manera que cualquier otra localización es excepcional y, en muchos casos, fruto de una transmisión defectuosa cuando no indicio de manipulación o falsedad” (Alfonso VI..., vol. I, p. 261).
} 


\section{NICOLÁs ÁVILA SEOANE \\ LA DATA EN LOS DIPLOMAS DEL EMPERADOR ENRIQUE IV Y DE SU ÉMULO ALFONSO VI DE LEÓN}

En definitiva, tanto la cancillería de Enrique IV como la de Alfonso VI datan la práctica totalidad de lo que expiden ${ }^{11}$, y coinciden en hacerlo hacia el final aunque no en idéntico sitio: la fecha germánica cierra el texto generalmente en línea aparte bajo los elementos de validación, mientras que la castellanoleonesa antecede a estos últimos.

\section{PALABRAS INTRODUCTORAS DE LA DATA Y SU DISTRIBU-} CIÓN.

La gran mayoría de las fechas del Sacro Imperio comienzan con el participio de dare (263 usan data, 83 data est y cuatro datum ${ }^{12}$ ) y siguen el modelo, ya de época carolingia, que Julius Ficker denominó ältere Datierung o fecha antigua ${ }^{13}$. El desglose más habitual que va a continuación lo hace por este orden: calendación, era cristiana e indicción, los años de reinado y la indicación del lugar tras el participio actum ${ }^{14}$. No hay un solo caso de los aquí seleccionados de la colección de von Gladiss y Gawlick hasta el año 1067 (E194) que no siga este esquema a rajatabla salvo el falso privilegio E167. A partir de ahí sí que encon-

${ }^{11}$ Ya la primera constitución del Código Teodosiano declaraba nulas las leyes imperiales carentes de fecha: Si qua posthac edicta sive constituiones sine die et consule fuerint deprehensa, auctoritate careant (el código entró en vigor el año 438 en Oriente y al siguiente en Occidente pero se trataba de una recopilación de leyes anteriores; la citada aquí es del 322: libro I, título I, constitución I); y el Liber iudiciorum promulgado por Recesvinto hacia el año 654 lo generalizaba: Scripturae quam diem et annum habuerint evidenter expressum atque secundum legis ordinem conscriptae noscuntur seu conditoris vel testium fuerint signis aut subscriptionibus roboratae, omnes habeant stabilem firmitatem (libro II, título V, ley I).

${ }^{12}$ La voz data puede emplearse también en otros lugares de la fecha, sobre todo acompañando a la calendación: 21 veces va detrás de ella, y otras once delante; además precede en una ocasión al segmento tópico (E489), en otra sigue a la indicción (E336), y en otra más, a los años del reinado (E274).

${ }^{13}$ Ficker le dedica un largo capítulo en el segundo volumen de su Beiträge zur Urkundenlehre, Innsbruck, 1878, pp. 237-311, que será el apoyo fundamental de Bresslau para referirse a este asunto (Manuale di Diplomatica..., p. 1072).

${ }^{14}$ Característica esencial de este prototipo es la división en dos partes: la crónica, precedida de data, y la tópica, encabezada por actum: "la date conserve assez longtemps sa division traditionelle en deux parties, et comprend, comme éléments essentiels: $1^{\circ}$ sous data, le quantième à la romaine, l'année de l'Incarnation, l'indiction et l'an du règne ou de l'empire; $2^{\circ}$ sous actum ou acta, l’indication du lieu. Elle se termine trés généralement par une formule d'apprécation. Le style ne commence à s'alterer qu'au commencement du XII ${ }^{\mathrm{e}}$ siècle; à partir du règne de Henri V on trouve de plus en plus frequemment des dates en une seule teneur, commençant par l'indication du lieu: Data Aquisgrani... “ (A. GIRY, Manuel de Diplomatique, París, 1894, p. 790). Bresslau (Manuale di Diplomatica..., pp. 1072-1073) estima que ello sólo se debe a la adopción en la cancillería carolingia de la fórmula de datación de las escrituras privadas, y que en ningún caso supone distinguir drásticamente entre el ritual protocolario (actum), y la expedición de su testimonio escrito (data). 
tramos 64 datas incoadas por la palabra anno que alternan con otras que siguen la pauta anterior. El orden usual de los demás elementos antepone el año al día y el mes ${ }^{15}$ : era cristiana, indicción, calendación, años del reinado, actum y data tópica.

Estamos embocando así la llamada feierliche staufische Datierung o fecha solemne suaba, pues de Suabia procedía la nueva dinastía Hohenstaufen, fórmula que quedará fijada bajo Federico I Barbarroja (1155-1190). Pero las referencias que Julius Ficker da sobre el período de transición hacia la nueva forma de fechar arrancan ya desde finales del reinado de Enrique V; Harry Bresslau, sin entrar en más detalles, sólo dice que con Enrique IV empieza a dejar de usarse la fecha antigua, dando paso a una gran variedad de fórmulas de datación durante la primera mitad del siglo XII, hasta que la cancillería de Barbarroja consolide la data solemne $^{16}$.

Esta arrancará con la locución acta sunt haec, e irá eslabonada así: era cristiana, indicción, años del reinado, fecha tópica encabezada por data, y calendación ${ }^{17}$; entre los diplomas de Enrique IV se halla en las dos versiones de un privilegio de confirmación de 1087 que no especifica día ni mes: Acta sunt hec Aquisgrani palatio anno Dominice Incarnationis MLXXXVII, indictione X, regnante Heinrico imperatore, Cunrado filio eius duce, anno regni eius XXXII, imperii IIII, Heinrico episcopo Leodiensi, Godescalco Traiectensi preposito, Dudekino decano (E394 y E395); hay que aclarar sin embargo que se trata respectivamente de una copia del siglo XIII, harto dudosa, y de una falsificación ${ }^{18}$.

En cambio en León el término inicial es por lo general facta (118 casos) o factum (otros doce) ${ }^{19}$, concordando con el casi siempre inmediato tenor documental, que será el objeto del próximo apartado. La expresión notum die, típica de los preceptos a principios del siglo XI, ha desaparecido casi por completo, junto con

\footnotetext{
${ }^{15}$ No es raro, en este patrón, que falten el día y el mes (21 veces), o que se retrasen, bien al final del todo (cuatro), o justo antes de la data tópica (cinco).

${ }^{16}$ J. FICKER, Beiträge zur Urkundenlehre, vol. II, pp. 311-327; H. BRESSLAU, Manuale di Diplomatica..., pp. 1072-1073.

${ }^{17}$ De nuevo hay que citar el manual de Ficker (vol. II, pp. 327-364), en el cual se funda Bresslau (pp. 1073-1074).

${ }^{18}$ Sólo hay seis datas de Enrique IV que no empiezan así, y varias son sospechosas: cuatro lo hacen con participios de facio: dos con facta est (el falso E371 y la copia interpolada E439), el falso E372, cuya fecha completa dice únicamente facta sunt haec in sancto Magontiensi sinodo, y uno con factum (E429). Otra arranca con acta (E489), y una más, directamente con la calendación (E490).

${ }^{19}$ Facta (86 veces), facta autem (27), factum (10), facta est (2), facta est autem (1), facta fuit (1), facta die agnito (1), factum est (1) y factum fuit (1).
} 
el propio tipo diplomático ${ }^{20}$ : residualmente queda en dos cartas reales y un privilegio (A7, A12 y A184). Los participios de dare, propios de la cancillería germánica, sólo aparecen dos veces con Alfonso VI: datum en una falsa misiva de 1080 (A69), y data en un privilegio a favor de Cluny del año 1090 (A110) ${ }^{21}$. Por tanto los componentes de la fecha se distribuyen preferentemente así: facta, tenor documental, día de la semana, calendación, era hispánica y regnante; el día de la semana y el regnante se omiten con mayor frecuencia; en cuanto a la data tópica, varía de ubicación las pocas veces que aparece.

Así pues, la data alfonsina difiere notablemente de la enriqueña en más de un aspecto: años del reinado, frente a regnante; era cristiana versus hispánica; tenor documental casi exclusivo de León, por indicción del Sacro Imperio; presencia casi general en un caso, y muy reducida en el otro, de la data tópica... También son distintas las palabras incoativas, ahora bien, tanto data como facta deben de referirse al momento de la conscriptio, y no al de la conclusión del acto jurídico; en el caso de Enrique IV no hay duda pues data ha de traducirse como 'dada, expedida o entregada': "è sicuro che data si riferisce alla documentazione: [...] era in rapporto con il tempo e il luogo nei quali la costituzione otteneva forza di legge mediante la sottoscrizione imperiale, oppure lo era con la consegna della disposizione o al destinatario o a un messo che la doveva portare al primo"22; mientras que en León ese más ambiguo factum, que en principio podría atribuirse tanto a la ceremonia en sí como a la expedición de su testimonio escrito, sabemos a ciencia cierta que se refiere a ésta última por ir ligado al tenor documental: facta carta, factum testamentum... ${ }^{23}$

\footnotetext{
${ }^{20}$ M. LUCAS ÁLVAREZ, El reino de León en la Alta Edad Media. La documentación real astur-leonesa (718-1072), León, 1995, pp. 238-243; S. CABEZAS FONTANILLA y N. ÁVILA SEOANE, “Cómo fechaba la oficina real...”, p. 62.

${ }^{21}$ Del resto, siete comienzan con la era hispánica, tres de los cuales la abren con era, otros tres con in era y el otro con discurrente era; tres más con el tenor documental; dos con perfectum; dos con el regnante; uno con roborata, y el falso A104 lleva la fecha en medio del texto incoada por Ita ut ab hac die quod est...

${ }^{22}$ H. BRESSLAU, Manuale di Diplomatica..., p. 1063-1064. Diferente es el caso del privilegio E452, que ya vimos que lleva dos fechas tópicas diferentes, incoada una por factum, y la otra por data, y que tal vez aquí sí esté distinguiendo entre la celebración y la conscriptio.

${ }^{23} \mathrm{Al}$ hablar de la data tópica veremos cómo en ocasiones va introducida por los participios roborata o corroborata que aluden a la validación.
} 


\section{EL TENOR DOCUMENTAL.}

En la cancillería del Sacro Imperio resulta muy excepcional ver dentro de la fecha la denominación que el propio escrito da de sí mismo, lo que tradicionalmente se ha convenido en llamar tenor documental; en rigor sólo lo encontramos en dos diplomas: el falso E371 de enero de 1085, cuya datación comienza facta est autem traditio, y la copia interpolada E439 de 1094, que dice facta est hec reformatio praescripta confirmationis. Hay otros seis casos sin más señalamiento que el demostrativo hic en nominativo neutro singular o plural: haec acta sunt in civitate Radanaspone (E148, original interpolado), facta sunt haec in sancto Magontiensi sinodo (falso E372), dos veces acta sunt hec Aquisgrani palatio (los ya citados documentos E394 y E395 dudoso y falso) y otras dos hoc actum est (E413 y E423).

Por contra, en los instrumentos de Alfonso VI es casi infalible: está en 137 de los 155 analizados. En 133 va inmediatamente después de las palabras introductorias, incoa otros tres, y sólo en una carta real va después del imperante ${ }^{24}$. Quince fechas lo llevan doble: Factum testamentum uel decretum (A36 o A43), Facta autem hac confirmationis carta serique testamenti (A189)...

El más frecuente es carta, que sale 54 veces tal cual, otras 43 su diminutivo cartula, y una cartulis. Series se repite en 25 diplomas. Otros nombres son más raros: en seis ocasiones aparece scriptura; testamentum y textum, cinco veces cada uno; decretum y privilegium, cuatro; regula, dos, y agnitio, paginolam y tenor, una. Aunque privilegium ${ }^{25}$, regula o agnitio ('reconocimiento') tienen un significado relativamente restringido, la mayoría de los conceptos son demasiado genéricos: carta o cartula, series, scriptura, testamentum (en su sentido etimológico de 'testimonio' ${ }^{26}$ ), textum, decretum ('orden, mandato'), paginolam o tenor. Por eso en muchos casos (102) llevan uno, dos y hasta tres genitivos precisándolo; los más

\footnotetext{
${ }^{24}$ La anómala construcción imperante rege Aldefonso de Calagurra usque ad Cuencam, facta carta in Era $M^{a} C^{a} X L^{a} V^{a}$, al revés de lo que suele ser habitual, es probable alteración debida al copista del Becerro galicano que nos lo ha transmitido (A. GAMBRA GUTIÉRREZ, Alfonso VI..., vol. II, 1998, p. 488).

${ }^{25}$ Según la actual nomenclatura diplomática, sólo es privilegio el A168, los otros tres son cartas reales (A19, A33 y A73). Manuel Lucas Álvarez se encuentra con el mismo problema en seis diplomas de Sancho II, y aclara que el término "no define una categoría diplomática a juzgar por la estructura de los textos en los que se emplea” (El reino de León..., p. 266).

${ }^{26}$ M. LUCAS ÁLVAREZ, El reino de León..., p. 265.
} 
frecuentes son: testamenti (48 veces), donationis (24), firmitatis (15) y confirmationis $(14)^{27}$.

Designar el tenor en la data ya era peculiaridad de los documentos asturianos y leoneses anteriores a Alfonso VI, pero sí son ahora novedosos los demostrativos hic e iste acompañando sobre todo a carta, cartula, privilegio, scriptura, series, testamentum o textum (35 casos de hic, 29 de haec, tres de hunc y dos de hoc; cuatro de iste, tres de ista y uno de este en castellano), y, más raramente, concordando con los genitivos delimitadores (siete veces huius y dos istius) ${ }^{28}$.

\section{EL DÍA, LA SEMANA Y EL MES.}

La calendación es prácticamente el sistema exclusivo en lo que respecta a Enrique IV para señalar el día y el mes: lo encontramos en 380 diplomas $^{29}$; hay 36 que sólo indican el año, y otros cinco el año y el mes (detrás siempre del genérico mense).

Siguiendo el patrón de la ältere Datierung, 330 veces la calendación es el primer elemento de la fecha, precedida sólo por el participio data o alguna de sus variantes $^{30}$. En 38 documentos va antes la era cristiana y luego la calendación, concentrados 35 de ellos entre 1070 y 1082. Más raro aún es ponerla justo antes de la parte tópica (E398, E413, E440, el falso E456, E470, E471 y E473), o cerrando el conjunto de la fecha (E148, E414, E417, E460 y el falso E461).

El indicador kalendas, nonas o idus sigue al numeral romano cuando lo exige. Sólo el privilegio interpolado E148 del 1 de mayo de 1065 alarga un poco la fórmula: prima die kalendas maii. El ordinal postridie ni aparece, y pridie en dos ocasiones (E76 y E140) frente a las 35 en que se prefiere el numeral II.

\footnotetext{
${ }^{27}$ Restan cuatro scripturae, tres concessionis, dos privilegii y sendos commutationis, contramudationis, decreti, genuitatis, imperialis, libertatis, oblationis, placiti, roborationis, stabilitatis y traditionis.

${ }^{28}$ S. CABEZAS FONTANILLA y N. ÁVILA SEOANE, “Cómo fechaba la oficina real...”, pp. 64-66.

${ }^{29}$ Aunque en diecinueve de ellos no se rellenó el espacio destinado a la calendación, ese era indudablemente el propósito. En otros dos casos falta sólo algún elemento: Data IIII februarii (sic) anno Dominice Incarnationis MLX, indictione XV, anno autem domni Henrici quarti regis ordinationis eius VIII (E31; no parece lógico pensar en el sistema boloñés, ajeno completamente a la cancillería de Enrique IV) y Data (espacio en blanco) aprilis anno Dominice Incarnationis MLXV, indictione III, anno autem ordinationis Heinrici quarti regis XII, regni vero VIIII, actum Mogoncie (E147).

30243 data, 81 data est y cuatro datum. Son anómalos los diplomas E489, cuya calendación empieza con acta, y E490, que carece de incoativo.
} 
El único documento que especifica el día del mes sin el sistema de la calendación, lo hace mediante el santoral: in festivitate Marci evangeliste (E430, 25 de abril de 1093). Además, el ya citado falso privilegio E280 en favor del monasterio de Hirsau, expedido el 9 de octubre de 1075 (Data est VII idus octobris anno Dominicae Incarnationis millesimo $L X X V$ ), lleva después de la aprecación una segunda fecha, correspondiente a la donación, que combina hasta tres referencias y añade el día de la semana: feria II, luna XXX, XVIII kalendas octobris, ipsa scilicet festivitate Sancti Aurelii; lo que ocurre es que no casan entre sí: la edad de la luna el lunes 14 de septiembre de 1075 era 17 y no 30, y la fiesta de San Aurelio de Riditio se celebra el 9 de noviembre ${ }^{31}$. Ninguna otra vez pone el día de la semana la cancillería de Enrique IV $^{32}$.

En cuanto a Alfonso VI, también es mayoritaria la calendación, con 127 de los 151 documentos fechados. Hay tres salvedades: un traslado en castellano de un privilegio original en árabe, que emplea el sistema boloñés (A168: este privilegio d'ont este translato es, fue escripto $V$ días andados del mes de iunio de Era mil e C e XL annos); un caso con el tiempo pascual (A110) ${ }^{33}$, y otro que sólo indica el mes (A150) ${ }^{34}$. El resto no pone más que el año. Y hay un curioso precepto de 1079 (A63), sobre el cual volveremos a propósito de la data tópica, con dos meses distintos, que para colmo no son consecutivos: facta kartula donacionis uel confirmacionis die quod erit VII ${ }^{a}$ idus aprilis octobris Era ICXVII.

Igual que en el Sacro Imperio, la calendación castellanoleonesa suele anteponerse al año, y, en la presente selección, con estos precedentes: tres veces las palabras introductorias, sesenta el tenor documental, otras doce el día de la semana, y dos más, la data tópica; también se ve pospuesta a la era hispánica en 47 ocasiones, y en tres más con el día de la semana intercalado.

La forma de calendar es como la de Enrique IV: los sustantivos kalendas, nonas o idus tras el posible numeral romano. Pero a diferencia de allí, donde sólo

\footnotetext{
${ }^{31}$ No fue casual la elección de San Aurelio, obispo de Riditio en Armenia muerto en Milán el 9 de noviembre de 475, cuyos restos reposaban en el monasterio de Hirsau desde su fundación en 830 .

${ }^{32}$ Explica Bresslau que fechar por el calendario litúrgico fue muy raro hasta mediados del siglo XII, y con el día de la semana, hasta comienzos del XIII (Manuale di Diplomatica..., pp. 10241026).

${ }^{33}$ Tampoco la oficina castellana databa con la fiesta del santo; además de este A110, fechado Pascae diebus, sólo hay dos menciones a la Navidad: in die scilicet Natalis Domini (el falso A32, expedido supuestamente el 1 de mayo y validado el 25 de diciembre de 1075), e Ista karta facta die Natalis Domini fuit corroborata in illo die erat Era $T^{\text {ma }} C_{\text {VIIIIX }}^{\text {ma }}$ et quod VIII kalendas $^{\circ}$ ianuarii (A74).

${ }^{34}$ El privilegio A172 lleva la calendación y el mes: facta carta roborationis notum mense marcii, feria $V^{a}$, XIIII kalendas aprilis.
} 


\section{Nicolás Ávila SEOANE \\ LA DATA EN LOS DIPLOMAS DEL EMPERADOR ENRIQUE IV Y DE SU ÉMULO ALFONSO VI DE LEÓN}

vimos un privilegio interpolado que añadía algunas palabras expletivas, en la de Alfonso VI esto es muy habitual: aunque notum die prácticamente deja de incoar la fecha, sí lo hace en la calendación 37 veces con diversas variantes ${ }^{35}$; llevan escuetamente los pronombres qui y quidam doce diplomas ${ }^{36}$; die, once ${ }^{37}$; concurrente, uno, y et quando otro.

Coinciden asimismo ambas cancillerías en eludir pridie y postridie: tampoco emplea postridie la de Alfonso VI, y pridie, sólo en dos de las quince ocasiones que lo permiten. Sí difieren en cambio en el empleo del pronombre ipse, que en Castilla y León reafirma la fecha en ocho de los dieciséis casos coincidentes con el día de las calendas, las nonas o los idus. Los profesores José Manuel Ruiz Asencio y José María de Francisco Olmos creen que es por ajustarse a la pauta clásica romana, ajena a cualquiera de sus corrupciones medievales como la calendación directa ${ }^{38}$; ahora bien, en las colecciones consultadas ese empleo de ipse cabe interpretarlo en todos los casos simplemente como intensivo: 'el mismo día de las calendas, las nonas o los idus ${ }^{39}$.

El día de la semana, ajeno según vimos a las datas del Sacro Imperio, consta en 22 diplomas de Alfonso VI. Por regla general va abriendo la data inmediata-

${ }^{35}$ Noto die (13), noto die qui fuit (7), notum die (5), noto die (4), et noto die quod est (2), die notum (1), et noto die quod erit (1), et noto die quod fuit (1), notato die (1), notum (1) y notum die quod erit (1).

${ }^{36}$ Et quod (3), et quoddum (3), et quotum quod est (1), que fuit (1), qui fuit (1), quod (1), quodum quod erit (1) y quotum (1).

${ }^{37}$ Die (5), die quod erit (3), die qui fuit (1), et quod dies (1) y sub die quod erit (1).

${ }^{38}$ El primero dice que "la doble posibilidad que tenía la mención de kalendas para el hombre medieval, regresiva hasta el 1 del mes, progresiva desde el 14 ó 16 del propio mes, dio lugar a que, en ocasiones, mediante un ipsas, diera el escriba a entender que se estaba refiriendo con seguridad a la fórmula clásica. La costumbre se aplicó después por extensión a nonas e idus” ("La medida del tiempo en la España cristiana en el año 1000”, en L. A. RIBOT GARCÍA, R. VILLARES PAZ y J. VALDEÓN BARUQUE (coords.), Año mil, año dos mil. Dos milenios en la Historia de España, vol. I, Madrid, 2001, p. 114), y el segundo: “como hemos visto, la kalendación [medieval] puede ofrecer numerosas modalidades para su uso; de hecho en la misma época parece que se dieron cuenta de este hecho y en algunas expresiones empieza a aparecer la palabra ipsas que parece indicar al lector que el uso de las kalendas es el clásico o tradicional, y así nos podemos encontrar expresiones como ipsas nonas aprilis, ipsas kalendas iunias, ipsus idus octobris que en cualquier caso tampoco debemos tomarnos como algo fijo, ya que en ocasiones se comprueba su uso como una moda o simple formulismo que no indica en realidad el uso tradicional de este cómputo" (Manual de Cronología. La datación documental histórica en España, Madrid, 2010, p. 201). Sobre la calendación directa y otros muchos problemas en la diplomática medieval puede verse el artículo de J. SARAIVA, "A data nos documentos medievais portugueses e asturoleoneses”, Revista portuguesa de História, 2 (1943), pp. 27-95, y el propio trabajo de Ruiz Asencio (pp. 110-115) que reconoce a Saraiva como su principal valedor en este punto.

${ }^{39}$ Sobre este punto véase también S. CABEZAS FONTANILLA y N. ÁVILA SEOANE, “Cómo fechaba la oficina real...”, pp. 66-68. 
mente detrás del tenor documental ${ }^{40}$. Se designa mediante el genérico feria, previamente determinado por el numeral romano correspondiente, excepto el sábado (sabbato, sabbatorum, sabatum) y el domingo (dominico). Al confrontar el día de la semana de las veinte de esas fechas en las que está la calendación completa, hay doce coincidencias, porcentaje de acierto similar al que encuentra Ruiz Asencio en los fondos de la catedral de León o de los monasterios de Sahagún y Otero de las Dueñas; de lo cual deduce que los errores en la calendación debían de ser muy frecuentes, afectando también, presumiblemente, a los casos inverificables por carecer de elementos de comparación; de todas maneras se trataría en principio de unos pocos días arriba o abajo ${ }^{41}$.

Así pues, unos y otros escribanos coinciden en el uso casi exclusivo del sistema de la calendación, así como en ponerlo hacia el principio de la data (con más rigidez en el Sacro Imperio), y también en el rechazo a las formas pridie y postridie. Por contra, los pronombres enfáticos, u otras expresiones no estrictamente indispensables, y las referencias al día de la semana son exclusivos de la Península Ibérica.

\section{EL AÑo.}

Sólo tres de los 422 documentos datados de Enrique IV prescinden de la era cristiana: hay dos falsos, fechados con la mera indicción (E282 y E406), y otro, también falso, sin más aporte cronológico que facta sunt haec in sancto Magontiensi sinodo (E372). En 321 ocasiones la era cristina va después de la calendación como segundo elemento de la data ${ }^{42}$ (ältere Datierung), en 86 es el primero ${ }^{43}$, y en seis, el tercero por detrás de la indicción ${ }^{44}$. Los seis casos restantes son cuando menos sospechosos ${ }^{45}$.

\footnotetext{
${ }^{40}$ Así ocurre en doce casos; además, en el privilegio falso A98, que omite el tenor, va a continuación de la fórmula introductoria. Otras seis veces se pospone a la era hispánica, y las tres restantes lo vemos tras la calendación o el mes o la data tópica.

${ }^{41}$ J. M. RUIZ ASENCIO, “La medida del tiempo en la España cristiana...”, pp. 108-109.

${ }^{42}$ Incluido el privilegio E459 que especifica el mes en vez de las calendas: Data mense februarii anno Dominice Incarnacionis M nonagesimo VIII.

${ }^{43} 64$ veces sin nada por delante, 19 con data, dos con data est y una con factum.

${ }^{44}$ E6, E303 (falso), E331, E369, E409 (falso) y E490.

45 E237 (falso): datum, data tópica, calendación, cancilleres participantes y era cristiana. E371 (falso) y E439 (copia interpolada): la era cristiana sigue al tenor documental. E394 (copia dudosa del siglo XIII) y E395 (falso): como segundo elemento tras la data tópica. E428 (falso 428): calendación, data tópica, canciller y era cristiana.
} 
Lo más habitual (340 veces) es que la cifra del año siga a la expresión anno Dominicae Incarnationis, donde el adjetivo Dominicae, concordando en femenino, determina a Incarnationis (en otras doce veces, sólo cambia el orden de las palabras: anno Incarnationis Dominicae); en catorce, se opta por dos sustantivos: anno Incarnationis Domini. Otra variante muy común es el ablativo regido por la preposición ab: ab Incarnatione Domini (41 veces), ab Incarnatione Domini Nostri Ihesuchristi (ocho) o ab Incarnatione Domini Ihesuchristi (una). Finalmente hay tres documentos que dicen simplemente anno Domini (E305, E311 y E388).

Ateniéndonos a la literalidad de estos enunciados, lo inmediato es considerar que la cancillería del Sacro Imperio en época de Enrique IV fechaba mediante la era cristiana según el estilo de la Encarnación, que hace comenzar el año el 25 de marzo, día de la Anunciación. El siguiente paso sería tratar de determinar si lo hacen a la manera de Florencia, que parte del 25 de marzo posterior al nacimiento de Cristo, o a la de Pisa, que, afinando teológicamente, lo hace desde el previo. De los 419 diplomas que hemos visto que llevan la era cristiana, podemos verificar el estilo en los 361 que especifican el mes (y también el día en el caso de marzo); pues bien, según la interpretación de la data de todos ellos, hecha por los editores Dietrich von Gladiss y Alfred Gawlik, el sistema florentino sería válido en 268, el pisano en 81 y quedarían doce discordancias. Lo que ocurre es que en los manuales de Cronología y de Diplomática leemos que la cancillería imperial empleó casi siempre el estilo de la Navidad desde Luis III (876-882) hasta que el Rey de Romanos Felipe de Suabia (1198-1208) introdujo temporalmente el de la Encarnación florentina $^{46}$. Y si comprobamos las mismas fechas propuestas por von Gladiss y Gawlik, haciendo ahora comenzar el año el 25 de diciembre, coinciden $339^{47}$.

\footnotetext{
${ }^{46}$ Véanse por ejemplo H. BRESSLAU, Manuale di Diplomatica..., pp. 1047-1048; A. GIRY, Manuel de Diplomatique, p. 109, o J. M. DE FRANCISCO OLMOS, Manual de Cronología..., pp. 170-171.

${ }^{47}$ Numerosos tratadistas advierten de que la expresión anno Dominicae Incarnationis debe entenderse a menudo como simple alusión a la era cristiana con independencia de cuál sea el estilo, empezando por el propio Jean Mabillon: "his insuper nonnulla hoc loco monere iuverit; primum est tam eos qui a Nativitate seu a kalendis ianuarii quam qui a Paschate annos numerabant, usos fuisse non raro iisdem verbis anni scilicet ab Incarnatione” (De re Diplomatica, París, 1681, p. 177). Harry Bresslau dice por su parte: “anche gli anni dell’Incarnazione non cominciano però affatto ovunque lo stesso giorno, anzi nel Medioevo vi sono principalmente sei giorni iniziali. Sono i seguenti: 1. Inizio dell'anno il 25 dicembre (stile della Natività). 2. Inizio dell'anno il 25 marzo (anno mariano), che può essere usato in un duplice modo [...]. 3. Inizio dell'anno a Pasqua (sporadicamente anche il Venerdì Santo). [...] 4. Inizio dell'anno il $1^{\circ}$ marzo (stile paleocristiano). 5. Inizio dell'anno il $1^{\circ}$ settembre (stile greco). 6. Inizio dell'anno il $1^{\circ}$ gennaio (stile della Circoncisione)" (Manuale di Diplomatica..., pp. 1046-1047). Según Alain de Boüard "I’expression anno
} 
Junto a la era cristiana y con la misma frecuencia, aparece el ciclo de la indicción en otros 419 documentos (el E46 y el E270 sólo llevan la era cristiana, y la ya citada falsificación E372 que sólo remitía a un sínodo en Maguncia). En casi todos los casos se yuxtapone a la era cristiana ${ }^{48}$ con esta invariable fórmula: indictione y número del año (del I al XV), pero sin indicar nunca el ciclo, vaguedad que ha de subsanarse mediante algún otro sistema de datación.

Tampoco es inmutable el comienzo del año de la indicción: la griega o bizantina arranca el primero de septiembre, la bedana (por Beda el Venerable) el 24, y la romana o pontificia el 25 de diciembre o el 1 de enero. La oficina del Sacro Imperio no siempre se atuvo al mismo tipo de indicción, ni siquiera durante un mismo reinado; por ejemplo, en la de Enrique III (1039-1056), cuyo año indiccional empezaba el 1 de enero, entre 1040 y 1042 y en 1045 se cambió a alguno de los estilos de septiembre, y también en los documentos despachados en Italia se tomaba el 1 de septiembre; bien es verdad que en los últimos años del reinado se generalizó el 1 de enero. Lamentaba Bresslau la falta de estudios al respecto sobre los subsecuentes emperadores, el primero de ellos Enrique $\mathrm{IV}^{49}$.

En los casos comprendidos entre el 1 de enero y el 31 de agosto, coinciden todos los cómputos de la indicción: de esa época del año quedan 264 diplomas, 172 de los cuales son de fecha fidedigna según la interpretación de von Gladiss y Gawlik. El análisis del último cuatrimestre de cada año muestra que en la cancillería de Enrique IV preferían la indicción bedana ${ }^{50}$.

Incarnationis ou ab Incarnatione n'est pas à prendre, on l'a vu, dans son étroite acception; c'est-àdire qu'elle n'annonce pas exclusivement l'emploi du style de l'Anonciation” (Manuel de Diplomatique française et pontificale, vol. I, París, 1929, p. 304). Y Cesare Paoli: "resta da fare un'osservazione sulla formula annus Incarnationis. Questa, in significato ristretto, si oppone all'altra annus Nativitatis, significa cioè un anno che comincia dal 25 marzo, non dal 25 dicembre; ma può benanche (como la formula generica, sopraccitata, di annus Domini) assumere un significato più largo, cioè indicare, semplicemente, anno tale dell'era cristiana, senza particolar riguardo al principio dell'anno da un giorno piuttosto che da un altro" (Diplomatica, Florencia, ed. revisada por G. C. Bascapè, 1942, p. 196).

${ }^{48}$ Diez veces se cambia el orden colocando primero la indicción, cuatro más va después de los años del reinado y otra combinándose con ellos (falso E68). En los dos diplomas falsos que no van datados por la era cristiana la indicción se sitúa: a continuación de los años del reinado en el E282, y tras la calendación en el E406.

49 "Per i documenti dei successivi salii e degli imperatori svevi mancano ancora ricerche specialistiche sul calcolo dell'indizione” (Manuale di Diplomatica..., pp. 1031-1033).

${ }^{50}$ Entre el 1 y el 23 de septiembre la griega va un año por delante: hay catorce diplomas, de los cuales sólo cuadra en dos, y en los demás, cualquiera de las otras tres. Del 24 de septiembre al 24 de diciembre la griega y la bedana van adelantadas un año respecto a la romana; se otorgaron 78 documentos: en seis ninguna se ajusta, en 44 las septembrinas y en 28 las romanas. Entre el 25 y el 31 de diciembre la indicción romana del 1 de enero lleva un año de retraso, y hay un caso que sigue ese cómputo, mientras que los otros seis admiten cualquiera de los otros. Quedan por último 
Sólo tres documentos añaden otras maneras de indicar el año, todos ellos falsos: la era cristiana y la indicción van acompañadas de la epacta y las concurrentes en el E237 y el E271, y en el E428 de la epacta nada más. Ésta va detrás de la indicción y acto seguido las concurrentes, resultando correctos todos los cálculos en las tres ocasiones. Las fórmulas son muy escuetas: epacta o concurrente y el oportuno cardinal romano.

A diferencia de la cancillería de Enrique IV y como es bien notorio, los escribanos de Alfonso VI recurren permanentemente a la era hispánica, con sólo dos excepciones en los 151 diplomas fechados por ellos. Casi la mitad de las veces (72) va al final del todo y, cuando no es así, suele seguir al tenor documental (44) o a la calendación (15) ${ }^{51}$. Salvo en el privilegio A18 (Facta cartula testamenti IIII kalendas iunii millesimo CXI), lo normal es que vaya incoada por la palabra era, bien sola (69 casos; tres veces más pone et era), con preposición (in era 35, sub era 23) o adjetivada (concurrente era 12$)^{52}$.

Los dos ejemplares sin era hispánica son el falso A162 visto en el primer apartado, cuya data alude a las de los diplomas que confirma (Facta cartulis testamentorum supradictorum secundum eras uniuscuiusque suprascriptas), y el privilegio A110, una donación en favor de la abadía francesa de Cluny hecha durante el tiempo pascual del año 1090, que combina la era cristiana y la indicción ${ }^{53}$ : anno ab Incarnatione Domini millesimo $X C^{m o}$, indictione $X I I I^{m a}$. Además, el muy sospechoso privilegio A67 del 8 de mayo de 1080 (otra merced a los cluniacenses, en este caso al abad Bernardo de Sahagún que en 1085 acabaría siendo primer arzobispo de la recién conquistada Toledo) mezcla los tres sistemas: era millesima centesima XVIII ${ }^{a}$. [...] Anno Dominice Incarnacionis millesimo octogesimo, indiccione quarta. Por lo común estas dos eras cristianas se han interpretado según el estilo florentino, pero Andrés Gambra advierte de que, como ocurre en el Sacro Imperio, podría tratarse del de la Navidad: “cabe suscitar a este respecto una hipó-

53 en los que no se indica el mes, más uno que no permite concretar el año, y por tanto no se puede averiguar qué indicción usaban.

${ }^{51}$ La encontramos también así: seis veces al principio, cuatro tras la data tópica, dos como único elemento de la fecha, y una al margen (copia A195 en el Becerro galicano), tras el día de la semana, después de la frase asistente ibi totius prouincie milicia, siguiendo a la fórmula regnante Domino Ihesuchristo y a continuación de la fiesta litúrgica.

${ }^{52}$ Seis difieren: de era (el diploma A168 en castellano), discurrente era bis dena et terna cum deçies dena atque necnon cum deçies çentena (A84, falso), era $M^{a} C^{a} X I I I^{a}$ eunte (A33, copia sospechosa), era tunc discurrente (A1), fuit corroborata in illo die erat era (A74, que volverá a salir debido a la data tópica) y notum die quod erit era (A12).

${ }^{53}$ Gambra infiere que pudo ser redactado por un escribano procedente del propio monasterio (Alfonso VI..., vol. I, p. 270). 
tesis complementaria: la posibilidad, frecuente al decir de Boüard en la Diplomática francesa, de que la expresión anno ab Incarnatione Domini se refiera al llamado estilo de la Navidad, que hace empezar el año de la era cristiana el 25 de diciembre” ${ }^{54}$. Teniendo en cuenta que los dos diplomas son posteriores al 25 de marzo y anteriores al 25 de diciembre, no se puede determinar cuál fue el método elegido pues ambos resultados coinciden. Y por lo que se refiere a la indicción, está mal calculada en el A67, y bien en el A110.

En síntesis, la diferencia fundamental entre los sistemas cronológicos para indicar el año en una y otra corte es: Sacro Imperio, era cristiana por el estilo de la Navidad e indicción generalmente bedana; Castilla-León, era hispánica.

\section{LOS AÑOS DEL REINADO Y EL REGNANTE.}

Nada menos que 413 diplomas de la cancillería del Sacro Imperio presentan algún tipo de cómputo relativo a Enrique IV: su edad (había nacido el 11 de noviembre de 1050); los años transcurridos desde la coronación como Rey de Romanos el 17 de julio de 1054; los de reinado efectivo tras la muerte de su padre Enrique III el 5 de octubre de 1056, y los de la investidura imperial el domingo de Pascua de 1084. Hay 21 referencias simples, 374 dobles y 18 triples que acostumbran a ir juntas y después de la indicción ${ }^{55}$ excepto las del falso privilegio E68 que llevan ésta intercalada.

Vemos los años de la coronación como Rey de Romanos en 322 ocasiones, y siempre encabezan este grupo cronológico tras el sustantivo anno, que luego ya no se repite ${ }^{56}$. Como es de suponer, disminuye drásticamente su presencia desde que Enrique IV se convierte en emperador, pero sin desaparecer del todo a pesar de lo farragoso que resulta el encadenamiento ${ }^{57}$.

En este apartado no vamos a encontrar tanta uniformidad como en los anteriores sino que, sobre todo en los años de la coronación como Rey de Romanos y del reinado, habrá múltiples opciones. Para los primeros se emplean diversas fórmulas que, incoadas siempre por anno, juegan con estos factores: el nombre y título reales (Heinrici, IV y regis), los determinantes ordinationis y domini, los atributos vero e invicti o su superlativo invictissimi, la conjunción autem, el de-

\footnotetext{
${ }^{54}$ Alfonso VI..., vol. I, pp. 270-272.

55357 veces. Otras 39 siguen a la calendación, catorce a la era cristiana, dos a la cita del mes y una a la del canciller.

${ }^{56}$ Falta excepcionalmente en E170, E342 y E413.

${ }^{57}$ Está presente en 302 de los 316 instrumentos datados antes de la Pascua de 1084, y sólo en veinte de los 106 fechados después.
} 


\section{Nicolás ÁVILA SEOANE \\ LA DATA EN LOS DIPLOMAS DEL EMPERADOR ENRIQUE IV Y DE SU ÉMULO ALFONSO VI DE LEÓN}

mostrativo eius y el adverbio quidem; reservándose el numeral del año generalmente para cerrar. El modelo más habitual con diferencia (175 veces) es anno autem ordinationis domini Heinrici IV regis y el cardinal ${ }^{58}$.

Volviendo a la anomalía de que tras la Pascua de 1084 los años de la coronación como Rey de Romanos aún sigan apareciendo esporádicamente, hay que decir que las pocas veces que lo hacen aluden también al título imperial y sustituyen el calificativo invicti por augusti, privativo de los emperadores. Resulta además muy curioso que en una misma frase el propio Enrique figure como IV rey de tal nombre, y III emperador (verbigracia el E358 del propio año 1084: anno autem domni Heinrici quarti regis tertii Romanorum imperatoris augusti ordinationis $X X X)$, lo que obedece a que Enrique I el Pajarero había sido rey de la Francia oriental desde 919 a 936 pero nunca emperador ${ }^{59}$.

\footnotetext{
${ }^{58}$ He aquí las demás alternancias, que siempre, salvo advertencia, acaban con el numeral del año: anno autem domini Heinrici IV regis ordinationis (21), anno autem ordinationis Heinrici IV regis (16), anno autem domini Heinrici IV regis ordinationis eius (12), anno autem ordinationis domini Heinrici (10), anno autem domini Heinrici (7), anno ordinationis domini Heinrici (7), anno autem ordinationis domini IV Heinrici regis (6), anno autem domini Heinrici IV regis invictissimi ordinationis (5), anno ordinationis domini Heinrici IV regis (5), anno autem ordinationis domini Heinrici regis (4), anno autem ordinationis domini Heinrici IV regis (3), anno autem ordinationis domini IV Heinrici (3), anno autem ordinationis quidem domini Heinrici IV regis (3), anno autem domini Heinrici IV regis (2), anno autem ordinationis domini Heinrici IV (2), anno domini Heinrici IV regis ordinationis (2), anno vero ordinationis domini Heinrici (2), anno autem domini Heinrici más el numeral del año y después regis (1), anno autem domini Heinrici IV regis y después ordinationis (1), anno autem domini Heinrici IV regis ordinationis quidem (1), anno autem domini Heinrici ordinationis (1), anno autem domini Heinrici ordinationis IV regis (1), anno autem Heinrici IV regis ordinationis (1), anno autem ordinationis domini Heinrici IV regis invictissimi (1), anno autem ordinationis quidem domini Heinrici III regis (1; el III es errata, véase en el siguiente párrafo la explicación sobre por qué sí es también correcto llamar Enrique III a Enrique IV pero sólo como emperador), anno autem ordinationis quidem domini Heinrici IV (1), anno domini Heinrici III ordinationis (1; otro error), anno domini Heinrici IV ordinationis vero eius (1), anno domini Heinrici IV regis ordinationis eius (1), anno domini Heinrici IV regis ordinationis quidem (1), anno domini Heinrici ordinationis (1), anno ordinationis domini Heinrici invictissimi regis (1), anno ordinationis domini Heinrici regis IV (1), anno ordinationis Heinrici IV regis (1), anno ordinationis Heinrici regis IV (1), anno ordinationis quidem domini Heinrici IV regis (1), anno quoque ordinationis domini Heinrici IV regis invictissimi (1), anno vero ordinationis domini Heinrici invictissimi regis (1), anno vero ordinationis domini Heinrici IV regis (1), ordinationis domini Heinrici IV invicti regis (1) y ordinationis vero domini Heinrici IV regis (1).

${ }^{59}$ He aquí las variantes, que siempre llevan detrás el numeral del año: anno autem domini Heinrici III Romanorum imperatoris augusti ordinationis (3 veces), anno autem ordinationis domini Heinrici III Romanorum imperatoris augusti (2), anno autem domini Heinrici III Romanorum imperatoris augusti ordinationis quidem (1), anno autem domini Heinrici IV regis III Romanorum imperatoris augusti ordinationis (1), anno autem domini Heinrici regis IV imperatoris III ordinationis eius (1), anno autem ordinationis domini Heinrici III imperatoris (1), anno autem ordinationis domini Heinrici III Romanorum augusti regni (1), anno autem ordinationis domini Heinrici IV regis III imperatoris Romanorum ordinationis quidem (1), anno autem ordinationis domini
} 
Un total de 276 diplomas permiten verificar el grado de fiabilidad de este cómputo $^{60}$, que no llega al 44 por ciento (120 aciertos y 156 fallos) de acuerdo con las fechas propuestas por von Gladiss y Gawlik, basadas primordialmente en la era cristiana como quedó advertido; lo cual le posterga a los demás tipos de años del reinado, cuyo crédito oscila entre el 55 y el sesenta por ciento. El salto de año sí se produce casi siempre de forma correcta el 17 de julio, pero hay períodos en que la gran mayoría de los despachados en un determinado año se asignan en bloque a otro, particularmente entre el 19 de julio de 1062 y el 1 de junio de 1069 (años IX a XV), cuando sólo aciertan cuatro de los 96 emitidos: los dieciséis del año IX se atribuyen al VIII; veinte de los veinticinco del X, al IX; dieciséis de los veinticuatro del XI, al XII; diez de los quince del XII, al XI; tres de los cinco del XIII y los dos del XIV, al XV, y siete de los nueve del XV, al XVI. Si prescindimos de esos siete años de desatino general, el porcentaje asciende prácticamente al 65 por ciento.

Los años del reinado efectivo son los más frecuentes, pues salen en 402 ocasiones: si acompañan a los de la coronación como Rey de Romanos, van en segundo lugar (314 veces), y si es con cualquier otro cómputo, van por delante precedidos siempre de la palabra anno $(87)^{61}$. Ya se ha apuntado que las soluciones aquí son muy variadas, distinguiendo ante todo si mencionan o no el título imperial, y si emplean u omiten el participio activo regnante.

La mayor parte de las fechas alusivas a Enrique IV sólo como rey, son lógicamente anteriores a la coronación imperial (311), pero subsisten 38 posteriores, las cuales, casi en su totalidad, aparte del indefectible anno (cuando no se indican los de la coronación real según acabamos de ver), combinan los sustantivos Heinrici (o Heinrici IV), regni, principis y domini, los adjetivos vero y serenissimi, la conjunción autem, el adverbio quidem o los demostrativos eius y eiusdem, y prevalecen las expresiones más sencillas: regni vero (236 veces) o simplemente regni (63), seguidas del numeral del año correspondiente ${ }^{62}$. En este grupo de datas que

Heinrici IV regis III Romanorum imperatoris ordinationis quidem (1) y regnante Heinrico imperatore III (el uso del participio regnante irá luego detallado).

${ }^{60}$ Es evidente la imposibilidad si falta el día o el mes, o si por descuido se quedó definitivamente en blanco el espacio prevenido por el escribano para los años en curso de la coronación como Rey de Romanos, o bien del reinado efectivo o del imperio.

${ }^{61}$ La única excepción es el falso privilegio del 9 de agosto de 1086, confirmatorio de la fundación y dotación del monasterio de Reinhardsbrunn, que los sitúa tras los años del imperio (E393).

${ }^{62}$ Las otras opciones, seguidas del numeral del año salvo que se indique otra cosa, son: anno autem domini Heinrici regni quidem (7), regni vero eius (5), anno autem regni domini regis Heinrici IV (3), anno autem domini Heinrici regis quidem (2), anno autem domini Heinrici regni eius 


\section{Nicolás ÁVILA SEOANE \\ LA DATA EN LOS DIPLOMAS DEL EMPERADOR ENRIQUE IV Y DE SU ÉMULO ALFONSO VI DE LEÓN}

no citan el título imperial sólo hay cinco con el participio regnante, todas ellas posteriores a la coronación por el antipapa Clemente III, que fue cuando se implantó definitivamente tal práctica: Heinrico anno nn regnante, dos veces, y regnante Heinrico nn, regnante Heinrico nn anno y regnantis quidem nn, una cada una.

Después de la Pascua de 1084 hay 53 fechas con los años del reinado efectivo, que también aluden a su condición de emperador llamándole Enrique III. 29 se construyen con los sustantivos anno (salvo elipsis), Heinrici (o Heinrici III), regni, imperatoris, Romanorum y domini, los adjetivos vero, augusti y serenissimi, la conjunción autem o el adverbio quidem, prefiriéndose las fórmulas anno autem domini Heinrici imperatoris regni quidem (doce casos), anno autem domini Heinrici III Romanorum imperatoris regni (cinco) y anno autem domini Heinrici III Romanorum imperatoris regni (cuatro), seguidas claro está del cardinal del año ${ }^{63}$. Y los otros 24 utilizan regnante, destacando sobre todo la forma regnante Heinrico III Romanorum imperatore augusto anno nn (once veces) ${ }^{64}$.

La fiabilidad de los años del reinado roza el sesenta por ciento (205 de los 347 diplomas verificables). Harry Bresslau, que pasa por alto el desacierto en los años de la coronación como Rey de Romanos, sí hace hincapié en el lío que se armaba con los del reinado y la indicción uno de los escribanos reales en las últimas décadas del siglo XI: "sotto Enrico IV un funzionario di cancelleria, attestato

(2), anno autem regni domini Heinrici (2), anno domini Heinrici regni (2), regni autem (2), regni autem eius (2), regni eius (2), regni vero eiusdem (2), anno más el numeral y a continuación regni domini Heinrici regis (1), anno autem domini Heinrici regni eius quidem (1), anno autem domini regis Heinrici IV (1), anno autem regni domini Heinrici regis IV (1), anno domini Heinrici IV regis (1), anno domini Heinrici regni quidem (1), anno regni serenissimi regis Heinrici (1), anno vero seguido del numeral y de Heinrici regis IV (1), anno vero domini Heinrici IV regis (1), domini autem Heinrici anno regni (1), regni autem eiusdem serenissimi principis (1), regni Heinrici anno (1), regni quidem (1), regni vero domini Heinrici III regis anno (1; privilegio E290 con errata en el ordinal del rey, que ha de ser IV).

63 Restan por añadir dos anno autem domini Heinrici III Romanorum imperatoris augusti regni quidem (1089 y 1091), y sendos: anno autem domini Heinrici III Romanorum imperatoris augusti regni vero (1087); anno autem domini Heinrici III Romanorum imperatoris regni quidem (1085); anno autem domini imperatoris regni quidem (1088); anno autem Heinrici imperatoris regni quidem (1098); regni vero domini Heinrici III imperatoris (1091), y regni vero domini Heinrici serenissimi imperatoris (1091). A continuación de todos ellos va siempre el número del año.

${ }^{64}$ Regnante Heinrico Romanorum imperatore augusto nn (3), regnante Heinrico Romanorum imperatore augusto anno nn (3), regnante Heinrico imperatore nn anno regni eius (2), regnante domino Heinrico Romanorum imperatoris augusto anno regni eius nn (1), regnante Heinrico III Romanorum imperatore augusto anno regni eius nn (1), regnante Heinrico imperatore nn anno (1), regnante Heinrico IV Romanorum imperatore augusto anno nn (1; E486 con errata inversa a la del E290 vista atrás; aquí ha de ser III) y regnante Heinrico Romanorum imperatore augusto anno nn regni (1). 
dal 1089 fino al 1095, non si orienta né con le indizioni né con gli anni di regno: con le prime rimane indietro più volte di una, due, e perfino di tre unità rispetto alla cifra esatta, e, quanto ai secondi, supera regolarmente di una, due o tre unità la cifra giusta”, 65 .

Encontramos los años del imperio en 96 de los 106 diplomas otorgados después de tal coronación. Regularmente se sitúan en segundo lugar dentro del grupo de eras de Enrique $I^{66}$. No hay tanta variedad sintáctica como en los casos anteriores, pudiéndose construir con o sin el participio de presente imperante (falta en 73 documentos y está en 23); los giros más habituales, seguidos del año correspondiente, son imperii vero (37 veces), imperii (15), imperante autem (13) e imperii autem $(11)^{67}$. De este cómputo dan en el clavo 46 de los 83 casos verificables.

Los años de vida son prácticamente anecdóticos, pues sólo están en tres privilegios originales expedidos en Goslar, la cuna de Enrique IV: E83 (9 de marzo de 1062), E84 (día 13 del mismo mes) y E206 (5 de agosto de 1068). Siempre cierran el conjunto en tercer lugar, y se construyen con vitae y el cardinal, que en el E206 se quedó en blanco; el E83 pone atinadamente XII, la edad púber del rey, mientras que el E84, que debería coincidir, dice por error vitae VII.

Hay además dos datas con los años de la investidura como Rey de Romanos del futuro Enrique V el día de Reyes de 1099. Se sitúan justo a continuación de los años del reinado de su padre: anno autem ordinationis filii eius Heinrici IIII $^{\circ}$ (E479 del 15 de julio de 1103) y anno ordinationis Heinrici regis incliti filii eius VII (E486; 28 de febrero de 1104), pero yerran ambas: la que se atribuye al año IV es en realidad del V, y la que dice VII es del VI. Hay que anotar al respecto que Enrique IV nunca figuró como Rey de Romanos en las datas de su padre Enrique III $^{68}$.

\footnotetext{
${ }^{65}$ Manuale di Diplomatica..., p. 1061.
}

${ }^{66}$ Siguen en 72 ocasiones a los años del reinado efectivo y en cinco a los de la coronación como Rey de Romanos; sólo en dos de ellas se utiliza la palabra anno que como sabemos sólo figura la primera vez. En otras quince van en tercera posición, precedidos por los años de la coronación real y los del reinado efectivo. Sólo en el falso privilegio E393 ocupan el primer puesto seguidos de los del reinado. En los diplomas falsos E371 y E425 y en el interpolado E439 representan el único dato cronológico de Enrique IV.

${ }^{67}$ Las restantes combinaciones sin imperante son: imperii quidem (3), anno autem imperii (1), domini Heinrici III imperatoris imperii eius (1), anno Heinrico III Romanorum imperatore (1), anno imperii Heinrici imperatore augusti (1), anno imperii magni Heinrici imperatoris augusti (1), imperatoris vero (1) e imperio vero. Y con él: imperante (4), imperante vero (4) e imperante autem vero (2). En ambos casos seguidas siempre del consabido numeral.

${ }^{68}$ H. BRESSLAU y P. KEHR, Die Urkunden Heinrichs III, Berlín, 1931, pp. 443-524 (docs. auténticos) y 568-573 (falsos); es el volumen V de los Monumenta Germaniae Historica. 
Las fechas de los diplomas castellanoleoneses son en este aspecto muy dispares de las que acabamos de ver: sólo una sexta parte (25) particulariza a Alfonso VI, casi siempre con los participios de presente regnante o imperante ${ }^{69}, \mathrm{y}$ sin hacer caso de los años de entronización. Normalmente se sitúa al final de la data (19 veces) ${ }^{70}$ y supone una novedad en la diplomática real de la oficina alfonsí, aunque el regnante era ya de larga tradición en la documentación privada asturleonesa $^{71}$.

La mayoría, 19 fechas, prescinden de cualquier mención al pretendido imperio hispánico, y en cuanto a la forma, lo mismo se resuelven con gran sencillez (seis regnante rege Adefonso, dos regnante Adefonso rege y sendas regnante Adefonso rex y regnante rex Aldefonso), que añaden alusiones divinas ${ }^{72}$ o nombran a la reina Berta de Tuscia ${ }^{73}$ o califican al rey en grado superlativo ${ }^{74}$.

Vimos al principio que en 1077 Alfonso VI se había arrogado el imperio peninsular desentendiéndose de cualquier procedimiento legítimo, circunstancia que se refleja en el uso esporádico y vacilante del atributo imperial en la documentación: dentro de la data sólo hay seis ocasiones donde de alguna manera se habla de Alfonso VI como emperador, y sin omitir nunca el título real. Andrés Gambra explica que ello ocurre por primera vez en la cláusula corroborativa de un privilegio del 17 de octubre de 1077 que eximía de tributos las propiedades del monasterio coruñés de San Antolín de Toques: ego Adefonsus, diuina misericordia imperator totius Hispania (A50) ${ }^{75}$. Hay dos datas aparentemente anteriores que ya consideran emperador a Alfonso VI, pero una es falsa y la otra nos ha llegado en una copia desordenada y resumida, de finales del siglo XVI, que tampoco ofrece las suficientes garantías ${ }^{76}$. Otras cuatro posteriores sí son fidedignas: reg-

\footnotetext{
${ }^{69}$ Únicamente varía el privilegio A39, que saldrá enseguida: regnum imperii Adefonsi rex.

${ }^{70}$ Otras cuatro se rematan citando a diversos personajes (A54, falso A93, A134 y A153), y en dos más va al principio (A191 y A195).

${ }^{71}$ M. LUCAS ÁLVAREZ, El reino de León..., pp. 487-658; S. CABEZAS FONTANILLA y N. ÁVILA SEOANE, “Cómo fechaba la oficina real...”, p. 75.

${ }^{72}$ Regnante Domino Nostro Ihesuchristo et me per ipsius misericordiam tenente sceptrum regni (A31 y el falso A32), regnante Domino Nostro Ihesuchristo cum Patre et Spiritu Sancto et me per ipsius misericordiam tenente sceptrum regni (A34), regno Domino Nostro Ihesuchristo et sub gratia eius ego Alfonsus (A64) y regnante Domino Nostro terra et polo et sub eius nutu tota in Yspania rege Adefonso (A73, copia sospechosa).

${ }_{73}^{73}$ Regnante Adefonso rege una cum Berta regina (A153, copia sospechosa).

${ }^{74}$ Recnante Adefonso uictorissimo rege (falso A93), regnante serenissimo domino Adefonso (A106, también falso) y regnante serenissimo rege Adefonso (A172).

${ }^{75}$ A. GAMBRA GUTIÉRREZ, Alfonso VI..., vol. I, pp. 694-695.

${ }^{76}$ Se trata de la carta real A26 fechada supuestamente en enero o febrero de 1075 regnante Adefonso iam dicto imperatore, y de un privilegio del 27 de agosto de 1076 donde se lee regnum imperii Adefonsi rex in Legione et in Castella (A39).
} 
nante et imperante serenissimo principe Adefonso (A92 de 1088 y A101 de 1089), regnante et imperante ego me medipso (A116 de 1091) e imperante rege Adefonso (A191 de 1107).

A estos veinticinco regnantes hay que sumar otro más, curioso por estar personalizado sólo en Cristo: Factum testamentum uel decretum regnante Domino Ihesuchristo sub era MCXIII et quod septimo idus februarii (A36 del 7 de febrero de 1076), lo que habrá que achacar a desliz del copista del quinientos que nos lo ha transmitido ${ }^{77}$.

El regnante le servirá a Alfonso VI, junto con la intitulación, para dejar constancia de sus conquistas, así como de la diversa prelación que merecieron a lo largo del reinado los distintos títulos que ostentaba, pues en todos los casos figura una lista más o menos larga de territorios (generalmente entre dos y cuatro): se cita León diecisiete veces; Castilla, catorce (en el falso privilegio A109 pone per omnem Castellam); Galicia, nueve; Toledo, otras tantas a partir del 30 de abril de 1088 (la falsificación A106 alude a la ciudad y no al reino: in Toletana ciuitate); Asturias, cuatro; cuatro también, Nájera, desde el 10 de julio de 1076 tras el asesinato en junio de Sancho IV y la anexión de La Rioja a Castilla; una, la Extremadura (falsa carta real A26), y otra, Pamplona ${ }^{78}$. El A191, de 1107, en vez de dar la nómina dice que Alfonso VI señoreaba de Calagurra usque ad Cuencam, y el A172, de 1103, in regnis suis sin especificar más.

Andrés Gambra considera que uno de los pasos previos de Alfonso VI para acabar llamándose emperador fue incorporar el topónimo Hispania, de resonancias cesáreas, a la intitulación real, y cuya primera constancia es del 17 de noviembre de 1072: ego Adefonsus, presenti tempore princeps et rex Spanie (A11) ${ }^{79}$. Hispania aparece también en seis regnantes, ya sea recalcando de paso su integridad (in omni Hispania, totius Yspanie, tota in Yspania y omni Hispania) ${ }^{80}$, o a secas (in Espania e in Hyspanie) ${ }^{81}$.

\footnotetext{
${ }^{77}$ Andrés Gambra juzga “de factura torpe” esta copia incompleta y vertida en parte al castellano (Alfonso VI..., vol. II, p. 88).

${ }^{78}$ En el privilegio A46 de 1077 por el que Alfonso VI duplicaba el censo anual que Fernando I había concedido a Cluny, y que es el testimonio clave de la alianza con los cluniacenses contra Sancho Ramírez (rey de Aragón que desde 1076 lo era también de Navarra) y el papa, resulta llamativo que figure Pamplona entre los dominios atribuidos a Alfonso VI.

${ }^{79}$ Alfonso VI..., vol. I, pp. 692-693.

${ }^{80}$ A40 de 1076 (también se citan Castilla y León), A64 de 1079, A73 de 1081 (copia sospechosa) y A106 de 1090 (falso; es el que pone además la ciudad de Toledo).

${ }^{81}$ A54 de 1077 y A93 de 1088 (falso; salen además Toledo y Galicia). Téngase en cuenta que todos los casos auténticos, con adjetivo o sin él, son anteriores a la conquista de Toledo en 1085, reino que ya nunca faltará, desplazando a Hispania.
} 


\section{NiCOLÁs ÁVILA SEOANE \\ LA DATA EN LOS DIPLOMAS DEL EMPERADOR ENRIQUE IV Y DE SU ÉMULO ALFONSO VI DE LEÓN}

Una observación: el sospechoso privilegio A67 del 8 de mayo de 1080 ya visto en el apartado anterior por ir datado con la era cristiana y la indicción, emplea además los años del pontificado de Gregorio VII: anno octauo Gregorii septimi pape. Aunque Hildebrando fue elegido por aclamación popular el 22 de abril de 1073 cuando ni siquiera era obispo, su investidura no tuvo lugar hasta el 30 de junio, y desde esa ceremonia deben contarse los años de papado. El autor de la falsificación no lo tuvo en cuenta y creyó impremeditadamente que el 8 de mayo de 1080 caía ya dentro del octavo año del pontificado de Gregorio VII ${ }^{82}$.

De todo lo expuesto se deduce que en el Sacro Imperio el manejo de los años del reinado dista mucho del que hace la corte de León. En la cancillería de Enrique IV se trata de eras que especifican los años transcurridos, ya sea desde el nacimiento, la investidura como Rey de Romanos, el reinado efectivo o la coronación imperial; frente a los instrumentos castellanoleoneses, que se limitan a nombrar al monarca reinante o poco más. Y mientras que son muy raros los diplomas enriqueños sin alguno de esos cómputos, sólo aparece en uno de cada seis de Alfonso VI, quien, por otra parte, los aprovecha políticamente para proclamar los estados que domina.

\section{LA DATA TÓPICA.}

Nada menos que 411 de las 422 datas de Enrique IV contienen el lugar de otorgamiento $^{83}$, y generalmente sirve de broche ${ }^{84}$. Siguiendo el esquema de la ältere Datierung, suele incoarse mediante el participio actum, bien sea aislado (346 $\operatorname{casos}^{85}$ ), o bien con algún aditamento (49) ${ }^{86}$; más raro es el uso del femenino

${ }^{82}$ Tampoco Andrés Gambra lo advierte: "se señala correctamente que fue emitido anno octauo Gregorii septimi pape” y en nota: “el octavo año del pontificado del papa Hildebrando dio comienzo el 22 de abril de ese año 1080” (Alfonso VI..., vol. I, p. 269). Sobre la datación por los años del pontificado puede verse por ejemplo J. M. DE FRANCISCO OLMOS, Manual de Cronología..., pp. 267-273.

${ }^{83}$ En cinco de ellos se había reservado el oportuno espacio en blanco para rellenarlo después, pero así se quedó.

${ }^{84}$ Pasa en 395 casos. Hay diez cuyo cirre difiere: siete, la calendación; una, el santo del día; otra, la ocupación de Roma, y una más, la presencia del ejército imperial; en cuatro va por delante (E255, E394 y las falsificaciones E237 y E395), y en uno ocupa el segundo lugar tras la calendación (falso E428), y luego queda el simulado privilegio E372 cuyo literal sale a continuación.

${ }^{85}$ Contando también siete datas en las que actum va detrás del topónimo.

${ }^{86}$ Todas las variantes llevan detrás el nombre del lugar en genitivo o locativo, salvo que se indique otra cosa: actum est (29, sólo en dos ocasiones el lugar va antes), actum apud (4), actum in (3), actum ad (2), actum est hoc (1), actum est in Langobardia (1), actum et datum más el nombre del lugar y urbe (1), actum in tal sitio y luego civitate (1), actum in, el lugar y después dicta (1), actum in obsidione castri vocabulo (1), actum in villa Thuringe quae dicitur (1), actum iuxta (1; en 
acta $(9)^{87}$. Las otras siete fechas tópicas se cimientan así: data o datum (4) ${ }^{88}$, la preposición apud (falso E428), el nombre pelado (Verone; E413), o implícito (Facta sunt haec in sancto Magontiensi sinodo; falso E372).

La mayoría de las veces se trata de poblaciones, pero hay once con otros emplazamientos: seis en cinco diferentes palacios ${ }^{89}$, dos en castillos ${ }^{90}$, una en el bosque de Kessel (actum in silva Ketela dicta, E91), otra en el río Fischa (actum iuxta flumen Fisek, E111), y la última en la escarpada peña de San Leo, cabeza del pequeño territorio de Montefeltro junto a la frontera de San Marino (actum in Montefredi ad petram Sancti Leonis; falso E425). Las segundas datas, ya mencionadas, de los privilegios E280 (falso) y E452 son muy específicas: apud Hirsaugiam in ipsis foribus aecclesiae dice una, y la otra in monasterio Sancti Zenonis de Verona. Otras tres fechas dan el doble topónimo de la plaza y su región: actum in villa Thuringe quae dicitur Wehemar (E386), actum est in Langobardia Patavii (E443) y Factum est in Italia Verone (E452). Resta señalar el falso privilegio E428 mediante el cual Enrique IV toma bajo su protección el monasterio de San Deodato en Los Vosgos, dado aput Montemveterem qui alio nomine Monsbeli dicitur $^{91}$.

En León la data tópica es mucho más esporádica: sólo se halla en veintiún documentos, incluyendo tres falsos y otro sospechoso; en 1926 decía Agustín Millares Carlo que "este dato no aparece de un modo regular hasta los promedios del reinado de Alfonso VII; con anterioridad es rara su presencia” ${ }^{92}$, circunstancia ya apreciada tres siglos antes por el historiador Diego de Colmenares al hablar de un privilegio de población de 1149: faltar en el instrumento el lugar donde se otorgó

un río), hoc actum est (1), hoc actum est apud castrum (1), y por fin in loco qui dicitur seguido del lugar y de actum atque datum (1).

${ }^{87}$ Cuatro de ellas sólo con acta, y una con acta est; todas de Espira. Además: acta est in palacio regis in Maguncia civitate (E371, falso), acta sunt haec más el lugar y palatio (E394 y falso E395), y haec acta sunt in civitate Radanaspone (E148).

${ }_{88}$ Data (E255 y E489), data est (E452) o datum (E237, falso) y después el lugar.

${ }^{89}$ Aquisgrán (acta sunt haec Aquisgrani palatio; E394 y falso E395), Goslar (actum Goslari in palatio regio; E282), Lieja (actum Leodi infra palatium; falso E478), Maguncia (acta est in palacio regis in Maguncia civitate; E371) y Roma (actum Rome in palacio nostro; E356 del 21 de marzo de 1084, al poco de conquistar la ciudad).

${ }^{90}$ Limburgo (actum in obsidione castri vocabulo Lemburs; E468) y Rivalta (hoc actum est apud castrum Riualte; E414).

${ }^{91}$ Es el actual pueblo de Monteveglio, en la provincia de Bolonia. En el segunda elemento del topónimo la etimología juega al escondite tras esa equívoca fonética, aplicable tanto a vecchioveterem ('viejo') como a belli ('guerra').

92 “La cancillería real en León y Castilla hasta fines del reinado de Fernando III”, Anuario de Historia del Derecho español, 3 (1926), p. 238. 
es descuido ordinario de aquel tienpo ${ }^{93}$. La novedad provoca titubeos en su formulación. Hemos visto que en el Sacro Imperio las fechas del modelo ältere Datierung se construyen en dos partes: la crónica, encabezada por data, y la tópica, por actum. Los diplomas de Alfonso VI pueden presentar o no esa dualidad: en diez casos hay un único verbo para toda la fecha - facta (nueve) o data (el otro) - mientras que en otros ocho sí que la crónica se indica con facta y la tópica con roborata o corroborata ${ }^{94}$, aludiendo al momento de la validación. En el privilegio A132 y en la carta real A151 sabemos que el otorgamiento y la suscripción fueron prácticamente simultáneos, como se deduce del eadem die de uno y eodem die de la otra ${ }^{95}$, en cambio, los diplomas falsos A26 y A32 de 1075 supuestamente se dieron en un sitio y se validaron en otro: Facta carta apud Legionem anno tercio in quarto mense post obitum Sancii regis in Zamora, et in Castromaior fuit tradita ad roborandum, y Facta carta donationis seu decreti kalendas may era TCXIII, fuit autem corroborata in Donnas in die scilicet Natalis Domini. Hay una data más con la misma distinción pero reflejando la parte tópica mediante scripta et confirmata: Facta autem hac scriptura firmitatis in era $M^{a} C^{a} X X X^{a} I I I I^{a}$ et noto die qui fuit XIII kalendas setembris et fuit scripta et confirmata in territorio de Castrofroilla, id est in Bustiello (A160).

Las otras dos fechas con topónimos también difieren entre sí: el privilegio A34 utiliza facta para el tenor documental, y luego corroborata (Facta fuit huius donationis carta et corroborata in Castroseriz die III feria Era TCXIII...), y en el precepto A63 la indicación cronológica va en el sitio habitual con facta, y en línea aparte, tras los elementos de validación, el lugar. El participio de corroboro no sólo acompaña los señalamientos locales, y si no, véase la carta real A74: ista karta facta die Natalis Domini fuit corroborata in illo die erat era $T^{\text {ma }}$ CVIIIIX ${ }^{\text {ma }}$ et quod VIII ${ }^{\circ}$ kalendas ianuarii.

${ }^{93}$ D. DE COLMENARES, Historia de la insigne ciudad de Segovia y compendio de las historias de Castilla, Madrid, 1637, p. 136. El privilegio, concedido por Alfonso VII al obispo de Segovia, era para poblar el lugar de Pozuelo, cf. N. ÁVILA SEOANE, Belmonte de Tajo hasta el siglo XVI en las fuentes documentales, Getafe, 2008, pp. 21-34.

${ }^{94}$ Unas veces con el escueto participio (roborata), y otras en voz pasiva plena, lo mismo en pretérito (fuit autem corroborata, fuit roborata), que en presente (roboratur), o con un gerundio (tradita ad roborandum).

${ }^{95}$ Aquí se ve que la cancillería castellanoleonesa seguía alternando la concordancia de dies, como lo permite su género ambiguo clásico. 
Además de los verbos facio, do, roboro y corroboro, pueden llevar las preposiciones in (mayoritaria: dieciocho casos) ${ }^{96}$ o apud (sólo tres), o directamente el nombre en genitivo (Burgis; A150).

Tampoco la posición del bloque tópico es algo fijo, pudiendo a veces encontrarlo prácticamente al principio, tras el tenor documental (ocho veces) ${ }^{97}$ o incluso justo a continuación de data (una), pero también al final del todo (seis), o tras la calendación (cuatro), o entre la era hispánica y el regnante (una), o separado del resto de la fecha, como en el precepto A63 recién visto.

Hay cuatro datas que precisan hasta el edificio de emplazamiento: los palacios de Lerma y Cea, el monasterio de San Salvador de Oña y el castillo de Monzón de Campos ${ }^{98}$. El A142 aclara que La Aguilera está en la ribera del Duero (in Aquilera super flumine Dorio), y el A160 se vale de un pueblo cercano mejor conocido: in territorio de Castrofroilla, id est in Bustiello ${ }^{99}$. Pero ninguna tan curiosa como la del precepto A63, de principios de abril u octubre de 1079, durante una de las campañas previas a la toma de Toledo, escrito en una trinchera junto al río Guadarrama: Et ista karta fuit facta et roborata hic in ipso flubio qui discurrit iusta de Toleto, id est Guadarrama, in fossato ${ }^{100}$.

Son palmarias las diferencias que existen en este punto entre una y otra cancillería: frecuencia de aparición (casi indefectible con Enrique IV frente a uno de cada siete documentos de Alfonso VI), colocación (al final en la del Sacro Imperio, o arbitrario en la de León), y verbo incoativo (actum en aquella, facta o roborata en esta).

\footnotetext{
${ }^{96}$ Lo más habitual es que vaya sola (once casos), pero hay excepciones: et in (2 casos, uno en la falsa carta real A26), vero in (1), in tal sitio civitate (1) o in urbem (1). En las dos restantes ocasiones in forma parte de las datas tópicas más complejas del precepto A63 y la carta real A160 que veremos enseguida.

${ }^{97}$ Contando la carta real A26: la primera fecha tópica va efectivamente tras el tenor documental, y la otra, tras la indicación del tiempo transcurrido desde el asesinato de Sancho II.

${ }^{98}$ In palacio de Lerma (A166), in regio palatio de Ceia (A171), in monasterio Sancti Saluatoris Oniensis (A118, falso) e in castro de Monzon (A188).

${ }^{99}$ La Aguilera es una pedanía de Aranda de Duero. Castrofruela pertenecía al actual término municipal burgalés de Santa María del Campo, en el límite con Palencia, y de él dependía Bustillo de Castrofruela; hoy las dos aldeas están despobladas.

${ }^{100}$ Ya se han comentado, tanto la extraña disposición de la data en ese premioso texto, como su equívoca cronología. Andrés Gambra explica que "la redacción y factura de este diploma, conservado a través de lo que parece el original, son muy descuidadas, circunstancia que puede imputarse al hecho de haber sido confeccionado durante la campaña militar a que se alude en la inusual precisión topográfica que cierra el escatocolo y de la que este diploma es la única fuente que conozcamos” (Alfonso VI..., vol. II, p. 157).
} 


\section{OTRAS REFERENCIAS CRONOLÓGICAS.}

En unas pocas datas del Sacro Imperio surgen referencias a prelados, cancilleres y a un hijo de Enrique IV, o bien a algún episodio militar, político o religioso.

El falso privilegio E263, fechado supuestamente el 5 de septiembre de 1073, alude al final al nuevo pontífice que acababa de ser coronado apenas dos meses antes y que terminaría convirtiéndose en el gran adversario del emperador: presidente Rome apostolicam sedem Gregorio VII qui et (sic: est) Hiltprandus. Con esa misma construcción de participio activo, pero precediendo a la data tópica, el también falso privilegio E461, del 23 de mayo de 1098, cita al arzobispo de Colonia Germán III (1089-1099): presidente sedi Coloniensi domno Herimanno archiepicopo. El interpolado E439, que von Gladiss y Gawlik fechan en 1094 conforme la era cristiana que exhibe, fue otorgado sub domno Sigefrido Mogontine sedis archiepiscopo eo tempore, quo ipse causa orationis in Galatiam ad Sanctum Iacobum perrexit, Huzmanno Spire episcopo, pero uno y otro dato son anacrónicos, pues la peregrinación a Santiago de Compostela del obispo Sigfrido I de Maguncia (1059-1084) tuvo lugar hacia $1072^{101}$, y el obispo Rodrigo, alias Huzmann, lo fue de Espira entre 1074 y 1090.

Los privilegios de 1087 E394 y E395, dudoso y falso, mencionan entre los años del reinado de Enrique IV a su hijo Conrado: regnante Heinrico imperatore, Cunrado filio eius duce, anno regni eius XXXII, imperii IIII; el primogénito se llamaba también Enrique pero murió recién nacido en 1071. En 1072 vio la luz Conrado que fue Rey de Romanos desde 1087 hasta que su padre le depuso en 1098 por ponerse de parte de Urbano II, y murió en 1101; ese título de duce corresponde a la Baja Lorena. El tercer varón fue el futuro Enrique V, cuyos años de la coronación como Rey de Romanos sirven para datar dos diplomas, según vimos en el apartado 6.

\footnotetext{
${ }^{101}$ He aquí el pasaje que le dedican Luis Vázquez de Parga, José María Lacarra y Juan Uría: “pocos años después [de hacerlo Roberto de Lieja en 1065] emprendió la peregrinación el primer alemán de cuyo viaje haya quedado constancia en una noticia histórica: el arzobispo de Maguncia Sigfrido I. Cansado del mundo y de los deberes de su cargo, se dirigió a Compostela quasi causa orationis, sin que sepamos si el viaje llegó o no a realizarlo por completo, puesto que ignoramos si fue a la ida o a la vuelta de Compostela cuando se detuvo en Cluny la víspera de San Miguel del año 1072, y allí aspiró a quedarse monje, pero hubo de regresar a Maguncia obligado por el abad del monasterio ante la noticia de que el anuncio de la vacancia de la sede daba lugar a manejos simoníacos, volviendo a encontrarse en ella en diciembre del mismo año" (Las peregrinaciones a Santiago de Compostela, vol. I, Madrid, 1948, pp. 48-49).
} 
En las falsificaciones E237 y E428 el nombre del respectivo canciller va antepuesto a la era cristiana: per manum Godefridi cancellarii et Olrici patriarche Aquileiae atque Petri cardinalis et Romani sacerdotis (expedido en Maguncia el año 1070) ${ }^{102}$, y per manus Ogerii Iporiensis episcopi Italie cancellarii (Monteveglio, 1092) ${ }^{103}$.

Acontecimientos políticos y militares salen tres: el sometimiento de Roma (actum Rome post urbem captam; E351, 22 de junio de 1083) ${ }^{104}$, la sublevación del marqués de Misnia Egberto II (presente domni Heinrici imperatoris exercitu, mox ut in Eggebertum fuerat iuditium pronunciatum; E386, 1 de febrero de $1086)^{105}$ y el sitio de Limburgo (actum in obsidione castri vocabulo Lemburs; E468, 16 de mayo de 1101) ${ }^{106}$, aparte del ya citado privilegio falso E372, dado in sancto Magontiensi sinodo (los obispos acudieron a Maguncia en la primavera de $\left.1085^{107}\right)$.

En León se personaliza con cierta mayor frecuencia, bien a miembros de la familia real, bien a otros monarcas peninsulares, o bien a eclesiásticos y nobles, pero tampoco mucho. En el discutido privilegio A153 de 1099 se nombra a la futura reina Urraca y a su marido Raimundo de Borgoña (in Gallecia Raymundo comite $^{108}$, una cum supra facti principis Adefonsi prole Urraka coniuge). En la

${ }^{102}$ Von Gladiss y Gawlik identifican al primer personaje con un oficial de Tréveris llamado Godefrido que no figura en las listas de cancilleres de Bresslau (Manuale di Diplomatica..., pp. 432-436), y al segundo con Ulrico I de Eppenstein, patriarca de Aquileia entre 1086 y 1121, muy posterior por tanto a la fecha atribuida al documento (Die Urkunden Heinrichs IV, vol. III, Hannover, 1978, pp. 899 y 929). Cardenales de nombre Pedro hubo dos en tiempo de Enrique IV, ambos italianos: San Pedro Damián, purpurado en 1058 y muerto en 1072, intervino en 1069 para evitar que el emperador se divorciara de Berta de Saboya; y Pedro Ígneo, que recibió el capelo en el consistorio de Albano de 1072 y falleció en 1089; para el primero cuadra el año de la era cristiana millesimo $L X X$, y para el segundo, la circunstancia de ser contemporáneo del patriarca Ulrico.

${ }^{103}$ El obispo Oggero de Ivrea sí aparece en el manual de Bresslau como canciller italiano desde comienzos de 1088 hasta la primavera de 1093 (p. 435).

${ }^{104}$ En realidad el otorgamiento se hizo durante el sitio de la ciudad, donde no entró el ejército imperial hasta el año siguiente.

${ }^{105}$ Egberto lideraba a los rebeldes sajones. Además de éste, en favor de la catedral de Utrecht, otros cuatro diplomas recogen donaciones de bienes expropiados al marqués de Misnia hechas por Enrique IV: a la misma sede los tres primeros, y a la de Eichstätt el último (E301, E388, E402 y E418).

${ }^{106}$ El conde Enrique I de Limburgo llegó a acumular demasiado poder cuando la mayor parte de los nobles de los alrededores hubo partido a la primera cruzada, y el emperador decidió sitiar la ciudad, que cayó al mes siguiente.

107 Tras la intervención de Roberto Guiscardo, Enrique IV y Clemente III huyeron de Roma, y, de regreso en Alemania, el emperador convocó este sínodo en Maguncia para apoyar a su antipapa.

${ }^{108}$ El rey entregó el condado de Galicia a su yerno probablemente en 1093, y ese es "el título oficial asumido sin excepciones [...] en los diplomas reales o propios” (Alfonso VI..., vol. I, pp. 481-482). 


\section{Nicolás ÁVILA SEOANE \\ LA DATA EN LOS DIPLOMAS DEL EMPERADOR ENRIQUE IV Y DE SU ÉMULO ALFONSO VI DE LEÓN}

carta real A54, fechada en 1077, sólo un año después de la conquista de La Rioja, están presentes el rey Sancho Ramírez de Aragón y Navarra, y los obispos de Pamplona Blas de Escaloz (1068-1078) y de Calahorra Munio (1066-1080): regnante Adefonso rex in Espania, Sancio Ranimiro regis in Pampilona uel in Aregona, Uelasius episcopus in Irunia, Munius episcopus in Nagera ${ }^{109}$. En otras tres cartas reales (A93 falsa, A156 y A173), que afectan a las diócesis de Lugo, León y Burgos, están nombrados sus respectivos obispos en la data ${ }^{110}$. En A151 y A154 encontramos asambleas de nobles y militares: circunstante concilio magnatum quorum nomina subscribentur (año 1099 en Castrofruela) ${ }^{111}$, y asistente ibi totius prouincie milicie (1100, León). García Ordóñez, tenente de Nájera y Calahorra, casado con una hermana del difunto Sancho IV de Navarra y enemigo acérrimo del Cid, aparece entre la fecha del fuero de Logroño, otorgado en 1095: regnante Adefonsso rege in Toletum et in Leon, subtus eius inperio comite domno Garssia dominante Nazera et Calahorra (A134).

Además del consabido precepto A63, datado en una trinchera del Guadarrama, otros cuatro diplomas reflejan en la fecha campañas militares: rege exercitum ad Zaragoza ducente (A142, 19 de mayo de 1097) ${ }^{112}$, coram magno exercitu militum qui ibant cum rege Valenciam decercare eam de moros (A166, 13 de febrero de 1102) ${ }^{113}$, coram omni suae expeditionis multitudine dum iter tenderet ad Aragon post celebratum concilium apud Legionem (A188, 8 de mayo de 1107),

${ }^{109}$ No parece casualidad que el documento proceda del monasterio oscense de San Juan de la Peña, donde se conservó hasta la Desamortización y el consecuente traslado al Archivo Histórico Nacional. Los obispos najerenses se resistían al cambio de sede a Calahorra ordenado en 1046, y siguieron residiendo frecuentemente en Nájera hasta mudarse a Santo Domingo de La Calzada a finales del siglo XII; desde 1221 la diócesis tiene el título conjunto de Calahorra y La Calzada.

${ }^{110}$ La primera es una donación a la catedral de Lugo: presidente in urbe Lucense episcopo (ha de tratarse de Amor, prelado entre 1088 y 1095). En la segunda Alfonso VI prohíbe el embargo de ganado de los canónigos de León, donde ejercía el obispo Pedro (1087-1112): domno Petro episcoporum religiosissimo ipsius predite sedis cathedram regente. Y en la tercera, una merced al monasterio de San Salvador de Oña, en la diócesis de Burgos, se cita al obispo García de Aragón (1097-1114): episcopo domno Garcia Burgensem sedem gobernante.

${ }^{111}$ El cuestionado privilegio A132 de 1095 alude asimismo en la data a la presencia de nobles y eclesiásticos, sin particularizarlos: et eadem die astantibus subscriptis in Toleto roborata.

${ }^{112}$ Después de la conquista de Huesca el 27 de noviembre de 1096 por Pedro I de Aragón, a primeros de mayo de 1097 Alfonso VI salió de León al frente de un ejército para auxiliar a su aliado el rey taifa de Zaragoza al-Musta'ín, pero un ataque almorávide lo impidió. El 19 de mayo, al poco de comenzar la campaña, el monarca castellano se encontraba en La Aguilera, cerca de Aranda de Duero, donde otorgó esta carta real.

${ }^{113}$ Los almorávides sitiaron Valencia en agosto de 1101 pero Alfonso VI no se decidió a intervenir hasta el año siguiente, llegando a las puertas de la ciudad en el mes de marzo de 1102 sin poder hacer otra cosa que proteger su evacuación por los cristianos; de camino a Valencia Alfonso VI otorgó la carta en su palacio de Lerma. 


\section{Nicolás ÁVILA SEOANE \\ LA DATA EN LOS DIPLOMAS DEL EMPERADOR ENRIQUE IV Y DE SU ÉMULO ALFONSO VI DE LEÓN}

y quando rex de Burgis egressus cum sola castellanorum expedicione super uascones et aragonenses iter direxit (A189, día 14 del mismo mes) ${ }^{114}$. Por último, la falsa carta real A26 de 1075 evoca el asesinato de Sancho II por Vellido Dolfos el 6 de octubre de 1072: anno tercio in quarto mense post obitum Sancii regis in Zamora.

\section{LA APRECACIÓN.}

Aunque ese escueto anhelo de ventura que suele rematar el diploma no forma parte de la data, sí va ligado a ella en la documentación de Enrique IV; la de Alfonso VI en cambio no lo emplea jamás.

Se halla en 395 de los 447 instrumentos de la cancillería del Sacro Imperio analizados en este trabajo, normalmente subsiguiendo a la fecha, pero hay catorce que mezclan una con otra: en cinco de ellos (dos son falsificaciones) toda la aprecación está dentro de la data, mientras que en los otros nueve cada una de ellas se divide en dos partes que se van alternando. Sólo hay un documento, pero falso (E368), sin fecha y con aprecación.

Consiste esta en una invocación divina más o menos explícita (Christi, Ihesu, Ihesuchristi, Domini, Domini Nostri) apoyada generalmente en la preposición in, el sustantivo nomine y los adverbios feliciter y amen; las fórmulas más frecuentes son in Dei nomine feliciter amen (158 ejemplos), o simplemente feliciter amen (82) ${ }^{115}$. Entre 1101 y 1105, en Espira, por entonces una de las ciudades más importantes del imperio y sede del panteón de la dinastía salia donde sería enterrado el propio Enrique IV, seis aprecaciones adjuntan al emperador: in Christi nomine ad salutiferam memoriam Heinrici tercii Romanorum imperatoris augusti feliciter amen; el año anterior, también en Espira, se había ensayado esto

\footnotetext{
${ }^{114}$ Los dos últimos textos citan un intento de frenar el avance de Alfonso I el Batallador hacia Zaragoza. El segundo está fechado in Era ICXLI, pero Gambra (Alfonso VI..., vol. II, pp. 482-483) cree que hay que retrasarlo a 1107, precisamente por la mención de esta campaña militar, la misma que figura en el anterior privilegio, datado indubitadamente en ese año.

${ }^{115}$ Resto de aprecaciones: in Christi nomine feliciter amen (28), feliciter (24), amen (14), feliciter in Christi nomine amen (13), in Christi nomine amen (12), feliciter in Dei nomine amen (10), feliciter in nomine Domini Ihesu amen (7), in nomine Domini amen (6), in Dei nomine feliciter (5), in Dei nomine amen (4), feliciter in nomine Domini amen (3), in nomine Domini feliciter amen (3), in nomine Domini Ihesu amen (3), feliciter in Christo (2), feliciter in nomine Domini Ihesu amen (2), feliciter in Christo amen (2), feliciter in nomine Domini (2), feliciter in nomine Domini Ihesuchristi amen (1), feliciter in nomine Domini Nostri Ihesuchristi amen (1), feliciter in nomine Sanctae et individuae Trinitatis amen (1), in Christo feliciter (1), in Dei feliciter nomine amen (1), in nomine Domini Nostri Ihesuchristi amen (1), in nomine Domini Nostri Ihesuchristi feliciter (1) e in nomine Sanctae et individuae Trinitatis amen (1).
} 
mismo con el obispo Juan I (1090-1104), firme partidario de Enrique IV: in Christi nomine ad salutiferam memoriam Iohannis venerabilis eiusdem loci episcopi feliciter amen ${ }^{116}$.

Siete llevan escritas en mayúsculas griegas las palabras Ihesu amen

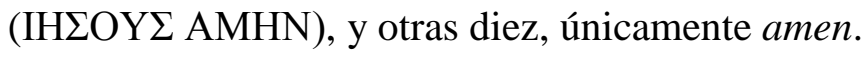

\section{CONCLUSIONES.}

Hemos ido viendo las diferencias de datación entre los conjuntos diplomáticos de Enrique IV y de Alfonso VI: en el Sacro Imperio la fecha se coloca antes de los elementos validativos, incoada generalemente por data; aplica la era cristiana según el estilo de la Navidad, la indicción bedana y los años del reinado, y es muy frecuente que se cierre con la data tópica, precedida del participio actum; por contra, en León va al final del todo, introducida por facta y seguida del tenor documental; se usa la era hispánica; los años del reinado se sustituyen por un genérico regnante que se aprovecha para hacer gala de los principales dominios de la monarquía o los recién conquistados, y la data tópica apenas está presente en una séptima parte de los casos, no obedece a una ubicación fija, y se apoya sobre todo en los verbos facio o roboro. La principal coincidencia es la calendación para indicar el día y el mes, aparte, claro está, del empleo exclusivo del latín, como corresponde a la época ${ }^{117}$.

Por regla general se observa que las pautas enriqueñas son mucho más estables, propias de una cancillería plenamente formada, mientras que la leonesa tardaría aún dos generaciones en institucionalizarse. Desde tiempos de Enrique III existían en el Sacro Imperio hasta tres oficinas emisoras, asentadas en Alemania, Italia y Borgoña, con un personal perfectamente jerarquizado: archicanciller (cargo meramente honorífico) ${ }^{118}$, canciller (habitualmente nobles de primer rango que

${ }^{116}$ Nombran al monarca los diplomas E466, E474, E475, E477, E488 y E489, y al obispo de Espira el E464.

${ }^{117}$ No hay más salvedades que las diecisiete aprecaciones en griego que acabamos de ver, $\mathrm{y}$ el fuero del castillo de Aceca del 5 de junio de 1102, sustentado en la traducción al castellano en 1235 de un supuesto original en árabe: Esta carta es traslatada del privilegio arávigo del qual es seellado de seello de cera en medio cascavel, e este seello es conoçudo en todos privilegios que son d'arávigo fechos por seello del Emperador que Dios aya mercet su ánima (A. GAMBRA GUTIÉRREZ, Alfonso VI..., vol. II, p. 437).

${ }^{118}$ Con Enrique IV los oficios de archicanciller de Alemania e Italia estuvieron vinculados respectivamente a las mitras de Maguncia y Colonia; el emperador nunca nombró archicanciller de Borgoña. 
tras desempeñar el oficio acababan de obispos) ${ }^{119}$, subcanciller y varias categorías de notarios y escribanos ${ }^{120}$.

No se podrá en cambio hablar de una verdadera cancillería castellana hasta Alfonso VII (aunque, con mengua de propiedad, haya aparecido el término en este trabajo). He aquí lo que, a este propósito, decía Agustín Millares Carlo: "la cancillería regia, irregularmente organizada hasta bien entrado el reinado de Alfonso VII el Emperador (1126-1157), expedía documentos con formulario muy diverso y difícil de caracterizar. Junto a diplomas que por su simple inspección se nos revelan como revestidos de indudable solemnidad, hallamos otros que, si bien son más sencillos, no responden ni a un formulario ni a un estilo diplomático úni$\cos { }^{121}$. Los investigadores que han podido constatar después esta ya axiomática observación del ilustre diplomatista se han esforzado por desentrañar cómo había ido desbrozándose el camino en los reinados anteriores. En cuanto a la época de Fernando I (1037-1065), Pilar Blanco Lozano habla de "primitivismo y desorganización”, con unos notarios reales, casi siempre eclesiásticos, que apenas si emplean el título, y que sólo empezarán a coordinarse bajo la disciplina del diácono Arias Díaz (1047-1065) ${ }^{122}$. Con Alfonso VI esos notarios y demás oficiales menudean más, aunque todavía no están determinadas sus funciones; a partir de 1095 destaca la figura de Pelayo Eríguez con quien aumenta la homogeneidad en las fórmulas y tipos, al tiempo que la oficina asume el manejo y expedición de la mayor parte de los documentos reales, hasta entonces elaborados en muchos casos por los propios interesados a su albedrío ${ }^{123}$. Dos diplomas de 1112 de la reina Urraca (1109-1126) hablan ya de un cancellarius, si bien se trata de copias que

\footnotetext{
119 Tampoco intervenían en la manipulación: "può darsi che fossero loro a dare le direttive per la produzione dei diplomi secondo l'ordine di documentazione impartito dal sovrano; ma con ciò di solito si esauriva anche i loro intervento nell'attività di documentazione. I cancellieri si preoccupavano senza dubbio ben poco della composizionee della forma, del dettato e della scrittura dei documenti; tutte queste incombenze ricadevano quasi sempre sui funzionari subalterni di cancelleria, e al loro umore, capriccio o abitudine individuale, alla loro accuratezza e acribia o trascuratezza e imprecisione dobbiamo imputare quasi tutti i caratteri mutevoli che ricorrono nella produzione documentaria di questi secoli” (H. BRESSLAU, Manuale di Diplomatica..., p. 414).

${ }^{120}$ H. BRESSLAU, Manuale di Diplomatica..., pp. 401-422.

121 A. MILLARES CARLO, “La cancillería real en León y Castilla...”, p. 232.

122 Colección diplomática de Fernando I (1037-1065), León, 1987, pp. 21-29.

123 B. F. REILLY, “The Chancery of Alfonso VI of León-Castile (1065-1109)”, en B. F. REILLY (ed.), Santiago, Saint-Dénis and Saint Peter, pp. 16-17; A. GAMBRA GUTIÉRREZ, Alfonso VI..., vol. I, pp. 104-113.
} 
requieren precauciones ${ }^{124}$. Durante el reinado de Alfonso VII la llegada de Hugo y Giraldo significará la cristalización definitiva de la cancillería castellana.

Por lo que hace a la data, con Alfonso VI se implanta en los diplomas reales el regnante, cuyo empleo hasta entonces se limitaba a escrituras privadas; se va extendiendo el uso de la data tópica, con tendencia a colocarla al principio de la fecha, lo que a la postre se impuso; y poco a poco van incorporándose rememoraciones de acontecimientos militares y políticos (campañas, revistas de tropas, concilios...), o personajes influyentes, como García Ordóñez o Raimundo de Borgo$\tilde{n} a^{125}$. En el Sacro Imperio todavía predomina la ältere Datierung, pero vemos ya un buen número de fechas que ensayan otras posibilidades; el cambio cuajará a mediados del siglo XII con la implantación de la feierliche staufische Datierung en época de Barbarroja.

Alfonso VI aparece mucho más preocupado que Enrique IV por afianzar en los diplomas su legitimidad y alardear de los dominios que abarca y de los que sigue conquistando. Junto a la intitulación, que es el lugar apropiado donde caben la nómina de los principales reinos, el título de rey o emperador de Hispania, el nombre de las sucesivas consortes o el de sus progenitores Fernando I y Sancha de León; la data será el otro fundamental recurso propagandístico (en el regnante la serie de reinos es más larga, figuran campañas contra Aragón y Valencia, y tampoco falta la importante conquista de La Rioja). Enrique IV en cambio prescinde de esas listas de posesiones, tanto en la intitulación ${ }^{126}$ como en los años del reinado, y pocas veces salen acontecimientos políticos o militares en la fecha.

Destacar por último el elevado número de anacronismos en las datas de ambos monarcas; sólo en 166 de las 422 conservadas de Enrique IV coinciden todas las referencias cronológicas; en las de Alfonso VI prácticamente carecemos de elementos de comparación, pero cuando aparecen, como el día de la semana, hay

${ }^{124}$ L. SÁNCHEZ BELDA, “La cancillería castellana durante el reinado de doña Urraca (1109-1126)”, en Estudios dedicados a Menéndez Pidal, vol. IV, Madrid, 1953, p. 592. En tiempos de Alfonso VI la carta real A26 datada supuestamente a comienzos de 1075 cita un magister Petrus Cidiz, chancellariy Aldefonsi regis, notuit, pero es falsa. p. 87.

${ }^{125}$ S. CABEZAS FONTANILLA y N. ÁVILA SEOANE, “Cómo fechaba la oficina real...”,

${ }^{126}$ La intitulación se ha perdido nada más que en uno de los 447 casos seleccionados en este trabajo (E435). Mientras fue Rey de Romanos Enrique IV empleó la sencilla fórmula Heinricus divina favente clementia rex en 289 de los 329 diplomas otorgados, cuyas variantes más habituales consisten en añadir el ordinal quartus, sustituir divina favente por gratia Dei, o cambiar el orden de las palabras; el título Romanorum rex sólo aparece en once documentos (cinco son falsos, y tres, copias interpoladas). Tras la coronación imperial se expidieron 117 diplomas con el nuevo título: Heinricus divina favente clementia Romanorum imperator augustus (25 veces), o, aún más, con el ordinal tercius (50); las demás alternativas suelen formarse con favente Dei, o Dei gratia. 
desajustes casi la mitad de las veces. Bresslau lo achaca a posibles errores de cuenta o de escritura, ya fuera al redactar los originales, o bien al copiarlos, así como a deficientes nociones sobre el uso de la numeración romana ${ }^{127}$. Pero también debía de resultar muy engorroso simultanear varios cómputos con distintos inicios de año: en el Sacro Imperio se podían llevar simultáneamente estos: la era cristiana partiendo del 25 de diciembre; la indicción, del 24 de septiembre cuando no otra; los años de la coronación como Rey de Romanos, del 17 de julio; los del reinado efectivo, del 5 de octubre, y los del imperio, del 31 de marzo.

${ }^{127}$ Manuale di Diplomatica..., pp. 1058-1061. 